\title{
When attentional and politeness demands clash: The case of mutual gaze and chin pointing in Quiahije Chatino
}

\author{
Kate Mesh ${ }^{1, *}$, Emiliana Cruz $^{2}$, Marianne Gullberg ${ }^{1}$
}

\begin{abstract}
Pointing with the chin is a practice attested worldwide: it is an effective and highly recognizable device for re-orienting the attention of the addressee. For the chin point to be observed, the addressee must attend carefully to the movements of the sender's head. This demand comes into conflict with the politeness norms of many cultures, since these often require conversationalists to avoid looking extensively at one another's heads and faces. In this paper we explore how the chin point is successfully used in just such a culture, among the Chatino indigenous group of Oaxaca, Mexico. We analyze interactions between multiple dyads of Chatino speakers, examining how senders invite visual attention to the pointing gesture, and how receivers signal that attention, while both participants avoid stretches of mutual gaze. We find that in the Chatino context, the senior (or higher-status) party to the conversation is highly consistent in training their gaze away from their interlocutor. This allows their interlocutor to give visual attention to their face without the risk of meeting the gaze of a higher-status sender, and facilitates close attention to head movements including the chin point.

Abstracts in Spanish and Quiahije Chatino are published as appendices.

Se incluyen como apéndices resúmenes en español y en el chatino de San Juan Quiahije. Son ${ }^{\mathrm{G}} \mathrm{ktyi}^{\mathrm{C}} \mathrm{re}^{\mathrm{C}}{ }_{\mathrm{in}}^{\mathrm{H}}$, ngyaq ${ }^{\mathrm{C}} \mathrm{ska}^{\mathrm{E}} \mathrm{ktyi}^{\mathrm{C}} \mathrm{no}^{\mathrm{E}} \mathrm{nda}^{\mathrm{H}} \mathrm{son}^{\mathrm{B}} \mathrm{na}^{\mathrm{F}} \mathrm{nga}^{\mathrm{J}} \mathrm{no}^{\mathrm{I}} \mathrm{ngyaq}^{\mathrm{C}}{ }_{\mathrm{lo}}^{\mathrm{E}} \mathrm{ktyi}^{\mathrm{C}} \mathrm{re}^{\mathrm{C}}$, ngyaq ${ }^{\mathrm{C}} \mathrm{ran}^{\mathrm{F}}$ $\operatorname{chaq}^{\mathrm{E}}$ xlya $^{\mathrm{K}}$ qo $^{\mathrm{E}}$ chaq $^{\mathrm{F}}$ jnya $^{\mathrm{J}}$ no $^{\mathrm{A}}$ ndywiq $^{\mathrm{A}}$ renq $^{\mathrm{A}} \mathrm{Kchin}^{\mathrm{A}} \mathrm{Kyqya}^{\mathrm{C}}$.

\footnotetext{
* Corresponding author

${ }^{1}$ Lund University Humanities Lab, Lund University, Lund, Sweden

${ }^{2}$ Department of Anthropology, Centro de Investigaciones y Estudios Superiores en Antropología Social (CIESAS-CDMX), Mexico City, Mexico
} 
Keywords: gesture, pointing, head gestures, visual attention, politeness, indigenous, Mesoamerica, Chatino

\section{Introduction}

The chin point, or chin jut, is a deictic gesture used to direct attention within physical space. It is a subtle signal, a seeming flick of the gesturer's head. A addressee who both sees and correctly interprets the signal will be prompted to shift their attention, searching for a relevant target in the space towards which the chin was extended.

In many parts of the world, the chin jut is a standard pointing device. Heads reorient, and eyes responsively shift, seemingly as a matter of course. Behind the apparent simplicity of the action, however, lies an elaborate choreography of visual attention, as gesturers invite and direct the gaze of their addressees, and as addressees signal and shift their attention.

In this paper we explore a context in which the choreography of chin pointing could easily come into conflict with local norms of politeness. In the Chatino community of San Juan Quiahije in Oaxaca, Mexico, conversationalists are expected to demonstrate respect through the avoidance of mutual gaze. Yet, even in a context where gaze towards the face brings a risk of impoliteness, chin points are regularly produced and received. To understand how pointing is accomplished in this context, we closely examine the interactions of three pairs of Chatino speakers, recorded during a direction-giving interview in which chin pointing was frequent. We analyze how participants invite and signal visual attention to the pointing action, even as they avoid stretches of mutual gaze.

\section{Background}

\subsection{Introduction to the chin point}

To point with the chin is to extend it, with noticeable speed, in the direction of a real-world target that an addressee can discern (and towards which they can shift their attention). It is a type of exophoric deictic head movement, in a 
larger family of head tosses (Enfield, 2001) that are optionally accompanied by other facial markers including lip funneling (Enfield, 2009; Mihas, 2017; Sherzer, 1973 , Sidnell \& Enfield, 2017) and nose wrinkling (Cooperrider \& Núñez, 2012). More often than not, a chin point is performed with the sender's gaze on their intended target.

The head and chin are dynamic during speech, and a chin point can be difficult to define in a way that excludes other common head movements. Yet several characteristics uniquely mark the gesture. First, the excursion of the chin from its starting position is relatively rapid, giving the impression of a quick "thrust" or "jut" that brings the chin to a visibly raised position (Cf. Enfield, 2009 Key, 1962, Eckert \& Hudson, 1988). Second, the chin point is typically preceded by a reorientation of gaze towards the target, provided that gaze is not already in the target's direction (Cf. Cooperrider \& Núñez, 2012, Enfield, 2001, 2009; Mihas, 2017). Finally, interactional context marks the head gesture as deictic, since speakers often produce the point in response to questions about locations of objects and alongside talk that indicates objects in real-world space (Cf. Clark, 1996: McClave et al., 2007). Chin points with these three features are used and recognized without difficulty in cultures around the world. The chin point has been documented in Asia and the Middle East (Enfield, 2001, 2009. McClave et al. 2007), Austronesia (Cooperrider \& Núñez, 2012, Wilkins, 2003), Africa (Ola Orie, 2009, Wilkins, 2003), and the Americas (McClave et al., 2007, Mihas, 2017, Sherzer, 1973). It has been claimed to be a universally available gestural resource (McClave, 2000; McClave et al., 2007).

Like other exophoric deictic gestures, the chin point is a device for managing the visual attention of two or more individuals, and coordinating that attention on a third object. The speaker or sender ${ }^{3}$ deploys the gesture to (re)direct the attention of the addressee. When the addressee recognizes the goal of the sender, and aligns their attention with the sender's on the relevant target, the

\footnotetext{
${ }^{3}$ We employ the term sender rather than speaker, recognizing that the communicator using a head point may be a user of spoken or signed language.
} 
two participants have established joint attention, a foundational function of human communication (Clark, 1996, Moore \& Dunham, 1995, Stukenbrock. 2020).

\subsection{Attentional demands}

A deictic gesture serves its purpose when an addressee's attention has been attracted and reoriented. For this to take place, the addressee must first observe the gesture, and in the case of the chin point, this requires that the addressee's visual attention be on or near the face of the sender (Enfield, 2001, 2009). Consequently, as the sender plans the chin point, it is necessary for them to monitor and respond to the addressee's visual attention cues (Stukenbrock, 2020). Research on the awareness of gaze has shown that communicators are highly sensitized to such visual attention cues, which include movements of the head and eyes (for a review, see Hamilton, 2016).

To participate in a joint attentional frame, the speaker and addressee must not only attend to a third object, but they must be aware of their mutual attention to that object (Moore \& Dunham, 1995). A part of the addressee's response to a pointing gesture, then, is to signal their attention shift, while it is the sender's role to monitor the addressee for such a response (Stukenbrock, 2020). It is typical for the addressee to shift their gaze to the target after the point is produced, providing a clear signal of their shift in attention (Sidnell \& Enfield, 2017) that is easily interpreted by the sender (Hessels, 2020). This gaze reorientation is not obligatory, however, and is less likely to take place when both communicators know that the addressee is familiar with the target and its location (Cf. Mihas, 2017), or are aware that the target is visually inaccessible. Like a shift in gaze, a verbal response to the chin point is common but not obligatory in the addressee, provided that some cue to the addressee's understanding of the communicative action is offered (Cf. Levinson, 2013). The attentional demand on both participants is relaxed once an appropriate response from the addressee has been performed (Sidnell \& Enfield, 2017).

Pointing is far from the only communicative action that requires the coor- 
dination of sender and addressee gaze. Across many types of social interaction, participants follow predictable patterns to attract and exhibit visual attention, continuously (re)shaping one another's expectations about how the interaction will progress (Cf. Cook, 1977, Duncan \& Fiske, 1977, Kendon, 1967, Kendon \& Cook, 1969, Kendrick \& Holler, 2017). The patterns of gaze coordination vary based on the nature of the communicative action the participants are engaged in. For example, senders are much more likely to shift their visual attention to addressees during the course of their talk if they are asking a question (Rossano et al. 2009: Levinson, 2013) or making another conversational move that invites the addressee's response (Bavelas et al., 2002, Ho et al., 2015). The patterns of gaze coordination are also highly sensitive to the direction of the addressee's visual attention at the outset of the sender's turn-at-talk. For example, a sender may attempt to attract the gaze of the addressee, and delay any pointing gestures, if the addressee's visual attention is not on them when they begin to talk (Cf. Goodwin et al., 1980; Goodwin, 1986; Mondada, 2007).

\subsection{Politeness demands}

For a chin point to be interpreted and followed, so that the communicators engage in a joint attentional frame, the sender and addressee alike must monitor cues produced on the face. These monitoring activities are most easily performed when each participant is looking at the other's eyes and face-i.e., during periods of mutual gaze (Streeck, 2014). Despite the utility of maintaining gaze on an interlocutor's face, and despite the fact that looking toward the interlocutor's face is common throughout an interaction Argyle \& Cook, 1976. Fehr \& Exline, 1987, Gullberg, 2003, Kendon, 1990), it is uncommon for two communicators to engage in long stretches of mutual gaze.

There are multiple motivations for gaze avoidance, some of which may be based on demands of language planning and processing. For example, speakers often look away from addressees when planning their speech (for a review, see Doherty-Sneddon \& Phelps, 2005). Another factor in gaze avoidance is the societal interpretation that long stretches of mutual gaze are impolite. Norms 
around gaze and politeness vary across societies, but several factors seem common to the construction of politeness around gaze. First, gaze avoidance is commonly interpreted to demonstrate deference (e.g., Brown et al., 1987; De Kadt, 1995, Keltner et al., 1997). Accordingly, averted gaze is often a required symbol of respect from a person of lower social status in an interaction (e.g., Ellyson \& Dovidio), whereas a person of higher social status may look more directly at their interlocutor, and look for longer stretches of time (Dovidio \& Ellyson, 1982; Snyder \& Sutker, 1977). Second, gaze on the face can be interpreted as a sign of attentiveness. It may therefore be selectively deployed by a person of lower status in an interaction to demonstrate respect for the interlocutor Brown \& Prieto, 2017; Brown \& Winter, 2019).

Across societies, the two common constraints around gaze and politeness place conflicting demands on communicators. The would-be enactor of politeness must show attentiveness, which requires them to gaze at the face of their interlocutor. They must also, however, demonstrate deference by not meeting the gaze of their interlocutor. These conflicting demands require participants in conversation to monitor the face of their interlocutor, but to avert their gaze in cases when the interlocutor looks towards them, in order to avoid a long stretch of mutual gaze. While conversational participants with a higher social status may be less constrained by these politeness demands, conversational participants with lower status will have a special obligation to avoid the impoliteness of sustained mutual gaze.

2.4. When attentional and politeness demands clash: the case of mutual gaze and chin pointing

The attentional choreography of the chin pointing event requires sender and addressee alike to demonstrate and respond to cues of visual attention. Frequent glances toward the face are necessary for both parties to the communication. Yet with each glance, the participants run the risk of meeting the gaze of their interlocutor, an act that may be judged impolite within the communicators' cultural setting. Perhaps the clash between politeness demands and attentional 
demands accounts for cases when chin points are produced but are not observed by the intended addressee, whose gaze is not on the sender's face (Cf. Sicoli, 2020 p. 100). Whether such cases are common, and the role that politeness demands play in them, is not yet known.

No research to date has systematically investigated the clash in attentional and politeness demands that arises in cases of pointing, and in particular in cases of chin pointing. Studies of politeness have paid little attention to the role of gaze outside of a small set of highly constrained laboratory studies (Brown \& Prieto, 2017, although for a recent call to take gaze strategies into account in contextualized politeness research, see). In a similar vein, research on the complex attentional choreography of pointing, and chin pointing in particular, has discussed the attentional demands of the deictic sequence without describing the risk of impoliteness that these demands bring. As a consequence, we know surprisingly little about how chin points are produced and interpreted, and how politeness norms are maintained, in naturalistic interaction.

\section{The current study}

In this study we investigate the attentional choreography of chin pointing in a context where it might be strongly threatened by politeness norms that discourage mutual gaze. In the Chatino community of San Juan Quiahije in Oaxaca, Mexico, local norms of politeness require speakers of lower social status to avoid meeting the gaze of interlocutors with higher social status. Yet chin pointing is nevertheless used frequently in conversations between interlocutors of differing social status.

To understand how attentional and politeness demands are met in the Chatino context, we recorded and analyzed conversations during a series of directiongiving interviews that were designed to elicit pointing actions. We paired a trained interviewer with three speakers, each of whom was in a different social position relative to the interviewer. This design allowed us to observe how

pointing was performed and received in distinct contexts where, to a varying 
extent, local politeness norms would discourage the participants from engaging in mutual gaze.

\subsection{Setting}

The Chatino people are the traditional inhabitants of a region of Oaxaca, Mexico, that stretches from the base of the southern Sierra Madre mountain range to the Pacific coast. Three distinct Chatino language families, encompassing a total of 17 language varieties, are spoken in the region (Campbell, 2013). All Chatino languages are marked by their high degree of tonality, with lexical and grammatical distinctions encoded using tone (Cruz, 2011). Our study is set in the community of San Juan Quiahije, where the Quiahije Chatino variety is spoken natively by nearly the entire population of 3,800 inhabitants (INEGI, 2020). The community is experiencing a rapid shift to Spanish bilingualism, and most people under the age of 40 are bilinguals (with many passive bilinguals in the older population). Children in Quiahije continue to acquire the Chatino language from birth, which distinguishes the community from the many surrounding Chatino communities that are undergoing a rapid shift to Spanish monolingualism (Villard \& Sullivant, 2016).

The politeness norms of the Quiahije community are not heavily documented. Nevertheless, gaze avoidance, and the avoidance of a face-to-face orientation between interlocutors, has been described as a feature of politeness in the community (Cruz, 2014). The avoidance of mutual gaze can be observed in day-to-day interactions in the community, where it is common to see individuals in a side-by-side (rather than mutually facing) orientation, with one or both parties gazing at the ground during an interaction. Gaze avoidance is especially common in interactions between men and women who do not have a kinship relationship, and in interactions between mothers- and daughters-in-law, who have a special obligation to show politeness (with the daughter-in-law obliged to exhibit deference towards her mother-in-law).

Gestures of the head, face, and body are routinely employed in conversations between interactants of all types in the Quiahije community, including 
interactants of differing social status. These gestures include pointing with the hand and chin - two well-documented practices for indicating targets within and outside the local community ((alias?) (alias?) (alias?)). The prevalence of chin pointing in particular makes the Quiahije community an ideal setting for exploring how this type of pointing behavior, with its special attentional demands, is accomplished by participants who are socially constrained to avoid stretches of mutual gaze.

\subsection{Methods and dataset}

\subsubsection{Participants}

Data for the current study were drawn from three 'walking interviews' in which one INTERVIEWER accompanied each of three SPEAKERS along a familiar trail and discussed well-known landmarks in the surrounding terrain (Cf. (alias?)). All interviews were performed in Quiahije Chatino by the same research assistant, a Chatino-Spanish bilingual woman aged 28. The interviewer was selected on the basis of her ability to pose questions consistently (targeting pre-selected landmarks in a designated order) while speaking in a natural manner, and engaging with speakers' responses thoroughly and naturally. The speakers were recruited by the interviewer and were selected on the basis of their near-exclusive use of Chatino. One speaker used Spanish in trade contexts, and two speakers showed at least some passive knowledge of Spanish (diagnosed outside of the interviews, as speakers heard demographic questions posed by the first author in Spanish and did not wait for a translation before replying in Chatino). Consent was obtained from the interviewer and from all speakers to use their research data, and to make their recorded images available to the public.

The three selected speakers had different social relationships to the interviewer, and we anticipated that politeness would be performed in slightly different ways across the three interviews. The first speaker was the interviewer's mother-in-law, a relationship that typically occasions a heightened display of politeness from both participants (with the daughter-in-law having a special 


\begin{tabular}{lllll}
\hline Age & Gender & Language use & Education & Relationship to interviewer \\
\hline 28 & Female & Chatino-Spanish bilingual & Elementary school & Self \\
67 & Female & Chatino speaker; passive knowledge of Spanish & None & Mother-in-law \\
69 & Male & Chatino-Spanish bilingual (strongly Chatino dominant) & Primary school & Older acquaintance \\
64 & Female & Chatino speaker; passive knowledge of Spanish & None & Older acquaintance \\
\hline
\end{tabular}

Table 1: Demographic information for all participants, including the relationship of each speaker to the interviewer

obligation to exhibit deference). We treated the meeting of the interviewer and her mother-in-law as a likely trigger for some form of mutual gaze avoidance. The second speaker was an older male acquaintance to whom the interviewer was not related. Typically, conversations between older and younger community members are marked by shows of politeness. The expectation for these politeness displays is increased when the speakers are of different genders, especially when they do not have a kinship relationship. We anticipated that the interactions between this older male speaker and our younger female interviewer would again occasion a display of politeness through the avoidance of mutual gaze. The third speaker was an older female acquaintance of the interviewer. While the interviewer would be expected to show politeness to the speaker because of her age, the strong politeness demands occasioned by her relationships to the other two speakers would be absent. We wondered whether this pair of participants might tolerate mutual gaze more than the other two participant pairs, reflecting a more relaxed standard for politeness in their interactions. Demographic information for all participants, including the relationship between each speaker and the interviewer, are summarized in Table 1.

\subsubsection{Recording procedure}

All three interviews were conducted along a trail leading to the peak of Kyqya $^{C} K_{c h e q}^{B}$ ('Thorn Mountain'), a location of religious and cultural significance to Chatino people. The recording group (interviewer, speaker, and camera operators) stopped at six preselected points along the trail to conduct a video-recorded conversation about how to identify and travel to significant lo- 
cal landmarks following paths from the current location. These questions were designed to elicit pointing gestures in naturalistic contexts (Kita, 2001).

All conversations were video recorded from two perspectives, providing front and side views of the participants. Recordings were made using Garmin Virb action cameras. Both the interviewer and the speaker wore a head-mounted Røde HS2 headset microphone. Each microphone was connected to a Røde Wireless Go transmitter which broadcasted to a receiver connected to one of the action cameras. Digital video was recorded by the first author and a trained research assistant. Video was shot in MP4 format with a video mode of 1080p and a frame rate of $30 \mathrm{fps}$.

Speakers talked with the interviewer for an average of 5 minutes at each of the six preselected points along the hiking trail. A total of 1 hour, 24 minutes of video footage of these conversations was recorded.

\subsubsection{Data treatment and coding}

The audio tracks from the two participants were combined to produce a single integrated sound file in WAV format. The video recordings providing a front and side view of the participants were synchronized using Adobe Premier. The digital video and audio files were transcribed, translated and coded using frame-by-frame analysis, performed in the video annotation software, ELAN (ELAN, 2020).

For this study, the point of entry to the dataset was the set of visible chin pointing acts produced by the three speakers. In a first-pass round of behavioral coding, the first author watched five minutes of the footage with the audio shut off, ensuring that there was no access to the content of the speech in the recordings. The first author proceeded frame-by-frame, first identifying all head movements that might constitute a chin point. Relevant head movements were identified via changes in the velocity of the head's movement (such as when the head was still, then reoriented rapidly so that the chin was extended, or when the head was slowly turning and suddenly tilted so that the chin jutted out rapidly, (Cf. Kendon, 1972; Kita et al., 1998, Seyfeddinipur, 2006). The first 
author then identified the stroke phase of the point, defined as the excursion of the chin from its initial position at the outset of the velocity change to its point of greatest extension (Cf. Cooperrider \& Núñez, 2012). Holds in the chin's extension and appreciable retractions of the chin were not included in the coding. The first and third authors met and reviewed the annotations in the selected five minutes of footage, and reached agreement about the accuracy of the frame-by-frame coding process and the definition of the gestural stroke. The first author then completed the same coding process for the entire dataset.

In a round of speech coding, the first and second authors reviewed all annotated cases of possible chin pointing in the footage with the sound audio turned on. They examined the larger interactional context around potential pointing behaviors (including the interviewer's prompt, to which the speaker was responding), determining whether the chin movement could be interpreted as deictic (McClave et al., 2007).

A second-pass round of behavioral coding was performed by the first authorthis time with the sound switched on, to facilitate the identification of turns-attalk (Cf. Sacks et al. 1974). For all chin points, the first author annotated the following features of the participants' behavior:

- the boundaries of the surrounding sequence, defined as the beginning and endpoint of the turn-at-talk in which the chin point took place, plus any adjacent turns-at-talk in which a relevant question or response was posed by the interviewer;

- the orientation of the two participants's heads and torsos at the outset of the sequence;

- any changes in head and torso orientation over the course of the sequence;

- any shifts in gaze that could be observed when the sclera of the participants' eyes was visible.

We elected to treat head direction as a primary marker of visual attention for this study. We made this choice because head direction could be annotated con- 


\begin{tabular}{ll}
\hline Interview participants & Total head points produced by speaker \\
\hline Interviewer and mother-in-law & 21 \\
Interviewer and older male acquaintance & 26 \\
Interviewer and older female acquaintance & 10 \\
\hline
\end{tabular}

Table 2: Distribution of chin points across interviews

sistently, and because head direction is understood by interactants themselves as a strong cue of visual attention (Cf. Kluttz et al., 2009). When a participant's sclera was visible, making it possible to discern their gaze direction, the additional source of information about their visual attention was noted by the first author.

The second author and a team of trained research assistants transcribed the talk in the footage surrounding the identified pointing events, including any relevant questions and responses from the interviewer. To transcribe Quiahije Chatino they used a practical orthography that is described in Appendix A The second author and research assistants also translated all of the selected talk into Spanish, a language shared with the other authors.

\subsubsection{Resulting dataset}

A total of 73 possible head gestures were annotated by the first author in the first pass of video coding. Sixteen gestures were determined not to be chin points in the second pass data review that included interactional context, leaving a dataset with 57 chin points for analysis. The distribution of chin points across the three interviews is presented in Table 2.

The video recordings that form the dataset for this project have been made publicly available in the Lund University Corpus Server. ELAN transcript files containing annotated physical behaviors, and transcribed and translated speech, have also been made available for review ((alias?) $)$. 


\subsection{Analysis - pointing, attention and gaze avoidance}

A close examination of the interactions in our video footage allowed us to identify the core elements of the chin pointing event, and to analyze how they were performed in settings where mutual gaze was avoided. We present our findings here.

3.3.1. The core of the chin pointing event - a predictable attentional sequence

Across the interactions in our footage, a clear pattern emerged. The interviewer and speakers reliably enacted a core sequence in which visual attention was displayed, recognized and redirected. Crucially, the sequence did not require participants to meet one another's gaze directly, and in many cases it was performed in its entirety without any stretches of mutual gaze. The standard sequence took the following format:

- The interviewer demonstrates visual attention to the speaker's face The interviewer proposes a target for the speaker to locate. If the interviewer is oriented away from the speaker, she turns her head and torso while speaking and reliably faces the speaker by the end of the question.

- The speaker responds by demonstrating visual attention to a relevant target, and by producing a chin point

The speaker responds to the interviewer's attention display by shifting their own gaze toward the direction of the proposed landmark (if they are not already looking in that direction); shortly thereafter they indicate the landmark using a chin point with an accompanying stretch of talk.

- The interviewer now shifts visual attention away from the speaker during or following the chin point.

Immediately following the speaker's chin point, the interviewer orients away from the speaker - typically, though not always, turning her head to face the target as she produces a (generally spoken) marker of acknowledgement. 
Example 1 - Interviewer and older woman enact the standard sequence; mutual gaze is tolerated. The core attentional sequence described above is exhibited in Example (1). This case features the pair of participants that we anticipated would show the most tolerance for mutual gaze, the interviewer and her older female acquaintance. The participants stand at an outcropping of rocks on the Kyqya ${ }^{C} K c h e q^{B}$ trail, with a view of the mountain range beyond. They assume an L-shaped formation, with the speaker facing toward the mountain range, and the interviewer positioned at a roughly 90-degree angle (Cf. Ciolek \& Kendon, 1980, Kendon, 1990). Both participants' heads are oriented toward the mountain range.

The interviewer begins by prompting the speaker to locate the distant town of Zacatepec. She shifts her head and torso during the prompt, so that by the end of her turn-at-talk her head is turned towards the speaker, demonstrating her attention to the speaker's face. The speaker glances towards the interviewer, and their eyes briefly meet. Neither participant shifts their gaze, giving evidence that a brief stretch of mutual gaze is acceptable to them both (line 1).

Shortly after the interviewer completes the prompt, the speaker turns her head in the direction of Zacatepec, exhibiting attention in the appropriate direction. The speaker locates the target town, saying: 'there is Zacatepec, now there it is.' Precisely as she pronounces the demonstrative expression kwaF, 'there', she produces a chin point in the direction of the town. The interviewer remains oriented toward the speaker until the chin point (line 2).

The interviewer responds to the chin point by shifting her head orientation away from the speaker and toward the paper script she holds in her hand, giving a clear demonstration of her shift in attention. Importantly, the sequence of the point and the responsive shift is tightly coordinated: in the video recording, the interviewer's head begins to turn in exactly the same frame in which the speaker's chin reaches its fullest extension. The interviewer looks at the script while listening to the speaker's full sentence. She then acknowledges the speaker's statement with a silent head nod (line 3).

This interaction in Example (1) includes the three core elements of the atten- 
tional sequence that we observed in our dataset: the interviewer's demonstration of attention on the speaker, the speaker's responsive demonstration of attention towards a relevant target, and the interviewer's rapid reorientation of visual attention away from the speaker.

(1) 201911206-R06-P03, 00:01:26
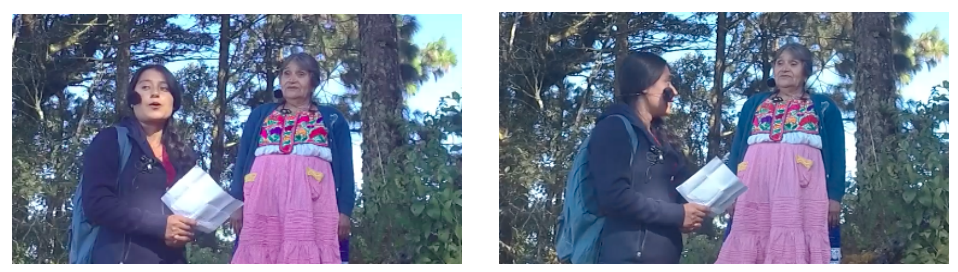

$1 \quad$ no $^{\mathrm{A}} \quad$ nga $^{\mathrm{J}} \quad \mathrm{tsi}^{\mathrm{C}} \quad \mathrm{a}^{\mathrm{J}}$

NMLZ be.3SG.HAB Zacatepec INT

'and the one that is Zacatepec?'

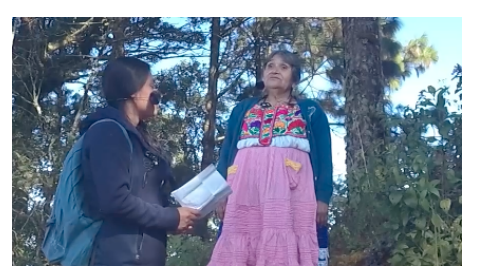

2

$\mathrm{mm}^{\mathrm{A}}-\mathrm{mm}^{\mathrm{H}} \frac{\mathrm{cp}}{\mathrm{kwa}^{\mathrm{F}}} \quad \mathrm{nga}^{\mathrm{J}} \quad \mathrm{tsi}^{\mathrm{C}} \quad \mathrm{ni}^{\mathrm{C}} \quad \mathrm{kwa}^{\mathrm{F}} \quad \mathrm{nga}^{\mathrm{J}}$

ACKN DEM:N be.3SG.HAB Zacatepec now DEM:N be.3SG.HAB

'uh-huh, there is Zacatepec, now there it is'

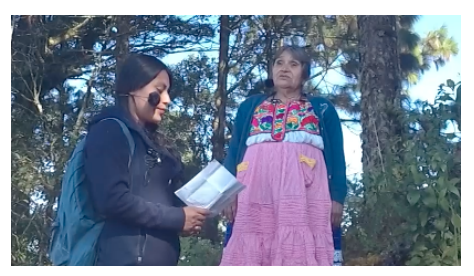

$3 \quad \frac{\text { nod }}{(1.0)}$ 
Example 2 - Interviewer and older man enact the standard sequence; mutual gaze is avoided. In Example (2), a similar attentional sequence is enacted by a pair of participants that we anticipated to avoid mutual gaze, the interviewer and her older male acquaintance. The participants stand side-by-side at an overlook on the trail, gazing into a mountainous landscape. The interviewer prompts the speaker to locate the distant city of Oaxaca. The interviewer turns as she speaks so that her head and torso face the speaker by the end of her verbal prompt, disclosing her attention to the speaker's face. The speaker remains oriented toward the landscape directly ahead, although the interviewer's turn should be accessible to him via his peripheral vision (line 1).

About 0.5 seconds after the interviewer completes her prompt, the speaker turns his head in the true direction of Oaxaca city. This is Northeast, which the speaker conveys by referring to the location of the sunrise: 'Oaxaca lies where the sun rises, (over) there now.' As he pronounces the word $n d w a^{B}$, 'to lie/rest,' he produces a chin point, extending his chin in the direction of the city. The interviewer's orientation remains toward the speaker until he produces the chin point (line 2).

The interviewer responds to the chin point by shifting her head orientation, this time to face in the direction of the indicated city. Again, the point and the responsive shift are tightly coordinated: in the video footage, the interviewer's head begins to turn exactly one frame after the speaker's chin reaches its fullest extension. The interviewer gazes silently toward Oaxaca while the speaker completes his turn-at-talk, after which she provides a verbal acknowledgement marker (line 3). 
(2) 20191217-R11-P04, 00:01:23
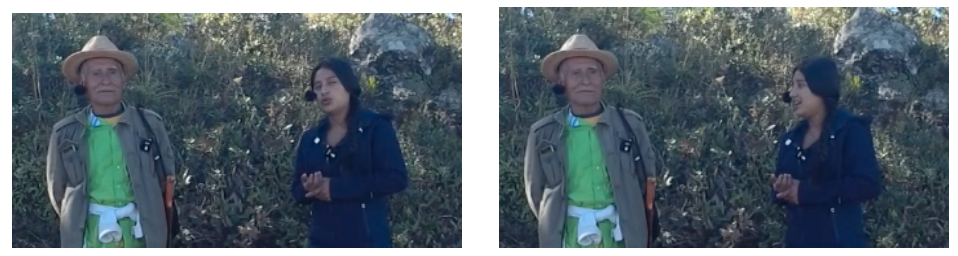

$1 \quad \mathrm{qo}^{\mathrm{E}}$ no $^{\mathrm{J}} \quad \mathrm{nga}^{\mathrm{J}} \quad \mathrm{lo}^{\mathrm{E}}$-ntqa $^{\mathrm{B}}$ janq $^{\mathrm{G}} \mathrm{a}^{\mathrm{J}}$

and NMzR be.3SG.HAB Oaxaca DEM:D INT

'and the (city of) Oaxaca?

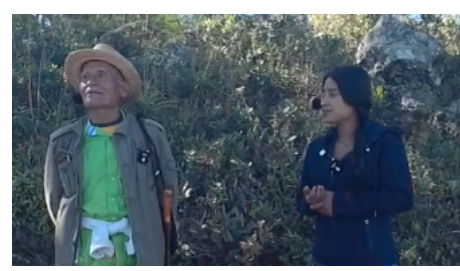

$2 \quad$ lo $^{\mathrm{A}}$-ntqa ${ }^{\mathrm{B}}$ janq $^{\mathrm{G}} \mathrm{ni}^{\mathrm{C}} \operatorname{sqen}^{\mathrm{A}} \frac{\mathrm{cp}}{\mathrm{ndywa}^{\mathrm{B}}} \quad \operatorname{ndywa}^{\mathrm{B}} \quad \mathrm{kcha}^{\mathrm{G}} \mathrm{re}^{\mathrm{C}}$

Oaxaca DEM:D now where lie.3sg.HAB lie.3sg.HAB sun DEM:1

'Oaxaca is where the sun rises, rises (over) there now'

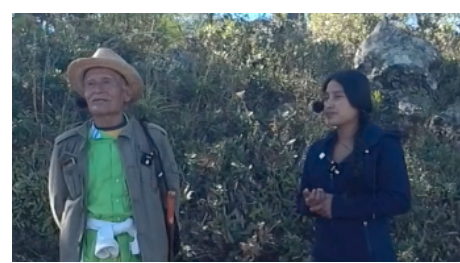

$3 \quad q^{2}{ }^{\mathrm{H}}-\mathrm{jan}^{\mathrm{A}}-\mathrm{janq}^{\mathrm{F}}$

ACKN

'uh-huh' 
Examples (1) and (2) are striking in their similarity, as both present a predictable attentional sequence surrounding the chin point. Notably, however, the examples represent very different patterns of physical orientation and gaze. When the interaction is between the interviewer and the older woman, the two participants orient toward one another, and gaze freely at one another's faces. The speaker easily ascertains that the interviewer is watching her face before producing the chin point.

When the interviewer is paired with the older man, the participants assume a side-by-side orientation. The interviewer turns her head toward the speaker, demonstrating her attention. The speaker responds to this display by signaling his own visual attention to a deictic target. The timing of the speaker's response suggests that he is monitoring the interviewer for visual attention cues, even when the interviewer is accessible exclusively through his peripheral vision.

Despite their differing patterns or orientation and gaze, both interviewerspeaker pairs display a core feature of the standard sequence: the speaker ascertains that the interviewer's visual attention is on them before they indicate their target. Both speakers appear to monitor the interviewer with ease.

\subsubsection{Participants adapt the attentional sequence when more than one point is produced}

While the core attentional sequence was recognizable for all instances of the chin point, there were many cases in which the participants expanded the sequence, minutely adapting the timing and number of attention displays from each party to the communication. Adaptations were especially common when a speaker used multiple pointing gestures to indicate a target.

Example 3 - Interviewer and older woman engage in an expanded sequence, mutual gaze is tolerated. Example (3) features the pair of participants that we anticipated to be more tolerant of mutual gaze. In this example the speaker produces multiple chin points toward the same target. This extended sequence presents an opportunity to observe the precision timing of the interviewer's attention display and the speaker's responsive deictic behaviors. 
The participants stand at an outcropping of rocks along the trail. They orient toward one another at a roughly 45-degree angle, facilitating easy visual access to one another. The interviewer prompts the participant to locate the place on the trail where the interview group stopped most recently. The interviewer turns her head toward the speaker during her prompt, and at the end of the prompt she produces an eyebrow flash - two signals of attention and engagement that are readily observable, since the speaker's gaze is directly on the interviewer. Again, when the participants' eyes meet, neither party averts their gaze. This stretch of mutual gaze is clearly acceptable to both participants (line 1).

Just as the interviewer completes her prompt, the speaker shifts her gaze toward the selected target and produces a silent chin point. She holds the chin at its position of fullest extension and describes the relevant location: 'above the Mischievous Rock.' The speaker's shift in attention toward the target is visible to the interviewer, whose gaze remains on the speaker until she produces the point (line 2).

Speaker and interviewer alike know that the landmark called Mischievous Rock is inaccessible from their current location: it is behind the interviewer and blocked from view by a stand of trees. Unsurprisingly, the interviewer does not shift her orientation toward the inaccessible target. Nevertheless, she performs the reorientation that has consistently followed a speaker's chin point: she turns her head to gaze into the space beside the speaker. Only after this gaze diversion does the interviewer look again to the speaker's face, while verbally acknowledging the speaker's statement. While this takes place, the speaker returns her gaze to the interviewer so that the two participants enter a stretch of mutual gaze (line 3 ).

While a typical sequence would end here, this expanded sequence contains an additional head point. The speaker produces this point immediately after the interviewer completes a head turn toward her, giving evidence of how closely she is monitoring the speaker's visual attention. The excursion of the speaker's chin coincides with the first word of the phrase, kwiqJ qyaA ngaJ, 'it's also 
downhill' (line 4).

Immediately after this second deictic action, the interviewer turns her head away while she partially repeats the speaker's description - a standard means of acknowledging a prior statement in many indigenous Mesoamerican contexts (Cf. Sicoli, 2020). Here again is the standard display of attention shift following a chin point, although without a turn toward the inaccessible target (line 5).

In this example the interviewer and speaker organize an expanded attentional sequence with precision timing - an achievement that is possible only if each participant visually monitors, and is immediately responsive to, the behaviors of the other. In this case, the necessary monitoring is accomplished with ease as the participants unreservedly gaze at one another, facilitating attention to even very subtle shifts of head orientation and gaze direction. 
(3) 20191206-R06-P05, 00:01:19
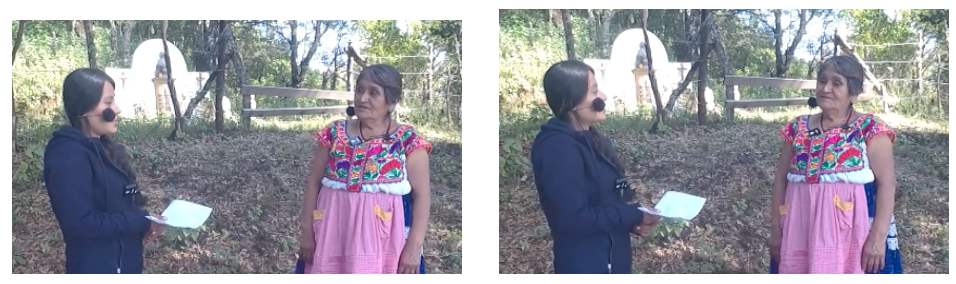

$$
\mathrm{la}^{\mathrm{E}} \quad \text { meru }^{\mathrm{J}} \text { jyaq }^{\mathrm{C}} \text { ti }^{\mathrm{F}} \text { qya }^{\mathrm{G}} \quad \operatorname{tqen}^{\mathrm{E}}-\operatorname{lan}^{\mathrm{E}} \quad \operatorname{ndan}^{\mathrm{E}}
$$

1 WHQ exactly place LOC downhill stand.3PL.COMP-INCL talk.3PL.COMP chaq $^{\mathrm{F}} \quad \operatorname{tsan}^{\mathrm{A}}$ janq $^{\mathrm{G}}$ language earlier DEM:D 'just where did we stop below to talk earlier?'

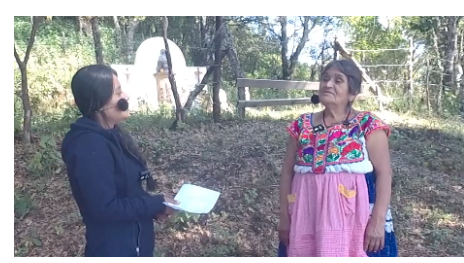

$$
\begin{aligned}
& \frac{\mathrm{cp}}{(0.3)} \mathrm{ke}^{\mathrm{G}} \text { kyqya }^{\mathrm{C}} \text { shyuq }^{\mathrm{E}} \\
& \text { rock above mischievous }
\end{aligned}
$$

'above the Mischievous Rock'

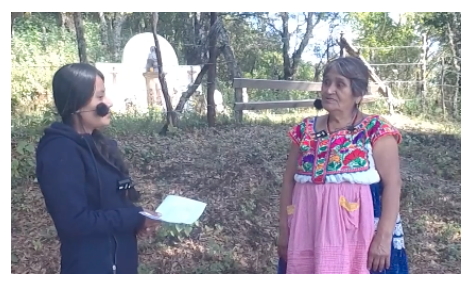

$3 \quad \mathrm{hmm}^{\mathrm{A}}-\mathrm{hmm}^{\mathrm{F}}$

ACKN

'uh-huh' 


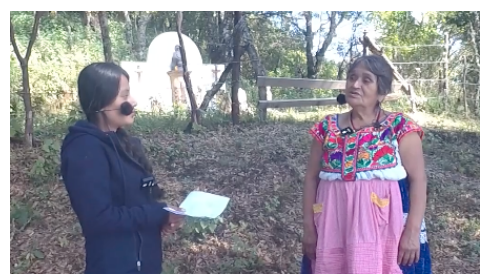

$4 \quad \frac{\mathrm{cp}}{\text { kwiq }^{\mathrm{j}}}$ qya $^{\mathrm{A}} \quad \mathrm{nga}^{\mathrm{J}} \quad \mathrm{janq}^{\mathrm{G}} \quad \mathrm{ni}^{\mathrm{C}} \quad \mathrm{janq}^{\mathrm{H}}$

also downhill be.3SG.HAB DEM:D now DEM:D

'it's also downhill now'

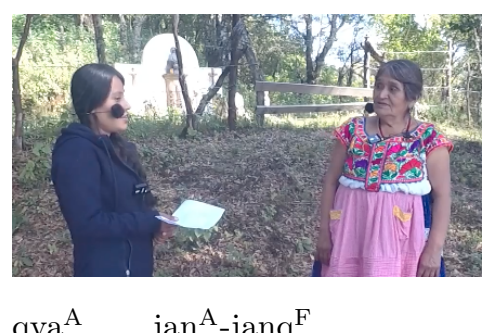

$5 \quad$ qya $^{\mathrm{A}} \quad$ jan $^{\mathrm{A}}$-janq ${ }^{\mathrm{F}}$

downhill ACKN

'downhill, uh-huh' 
Example 4 - Interviewer and mother-in-law engage in an expanded sequence; mutual gaze is avoided. Example (4) features the interviewer and her motherin-law, a pairing that we anticipated to elicit mutual gaze avoidance. In this example, one element of the core attentional sequence is expanded as the speaker produces two gestures toward her target: an initial chin point, immediately followed by a manual point.

The participants stand at a scenic overlook and assume an L-shaped configuration, with the interviewer facing the overlook and the speaker positioned at a roughly 90 -degree angle, facing the receding trail. The interviewer prompts the speaker to locate the trail's end. Following a familiar pattern, the interviewer shifts her head orientation from the interview script to the speaker while she voices the prompt. While the interviewer is not in the speaker's direct line of gaze, her display of visual attention is doubtless perceptible in the speaker's peripheral vision (line 1).

The speaker responds by describing the location of the trail's end: 'it's just uphill, this way now.' Her gaze is already in the direction of the trail's end, and she maintains this display of attention as she forms a chin point alongside the expression, $q i n^{K} t i^{H} k y a q^{B}$, 'just uphill.' The speaker holds her chin in the extended position and begins to raise her hand to point to her target. As she extends her pointing hand, she adds $t i^{H} r e^{C}$, 'this way.' The interviewer maintains her orientation towards the speaker throughout both gestures (line 2).

About 0.5 seconds after the speaker lowers her gesturing hand, the interviewer shifts her head and torso orientation to face the trail's end, signalling that she is bringing her visual attention in line with the speaker's. She briefly acknowledges the speaker's statement (line 3).

In this sequence, the interviewer maintains her gaze on the speaker throughout the chin point and the immediately following manual point. Her sustained gaze provides evidence that she visually monitors the speaker for any relevant gestural behaviors during the speaker's turn-at-talk, and shifts her attention only after she judges all of the relevant gestures to be complete. This type of 
attention to multiple signals is vital to the achievement of joint attention, as speakers convey different types of information in distinct deictic gestures (Cf. Atkinson et al. 2018, ((alias?) $)$, necessitating the addressee's attention to the entire deictic constellation.

(4) 20191130-R04-P03, 00:02:42
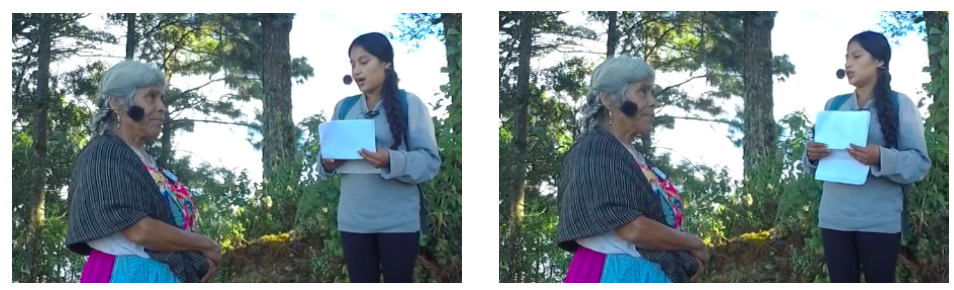

1

$$
\mathrm{la}^{\mathrm{H}} \quad \text { jyaq }^{\mathrm{F}} \quad \mathrm{no}^{\mathrm{H}} \quad \mathrm{janq}^{\mathrm{G}} \mathrm{ne}^{\mathrm{C}}
$$

WHQ extent be.3SG.HAB DEM:D now 'how far away is it now?'
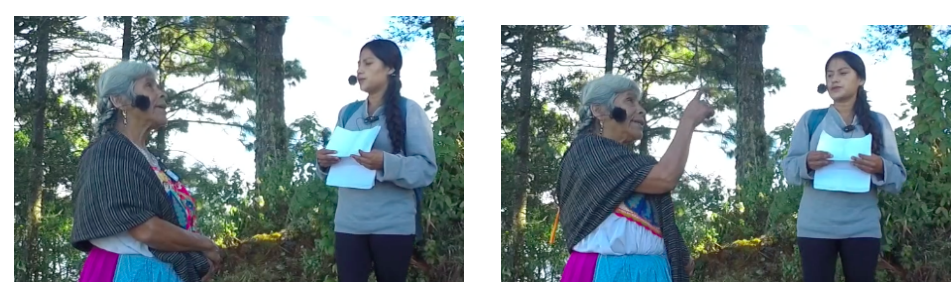

$$
2
$$

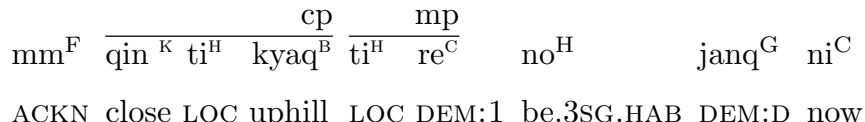

'it's just uphill, this way now'

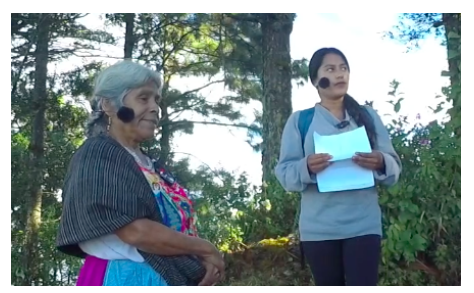

$3 \quad$ jan $^{\mathrm{A}}$-janq $^{\mathrm{F}}$

ACKN

'uh-huh' 
Examples (3) and (4) present elaborated versions of the core attentional sequence, in which participants organize their attention displays around multiple deictic actions. Again, the two interviewer-participant pairs differ in the physical formations that they assume, and in their gaze patterns over the course of the sequence.

The interviewer and the older woman turn toward one another and frequently gaze at one another's faces, and they do not appear to avoid the resulting stretches of mutual gaze. For these two participants, visual access to one another's faces allows for a rapid response to subtle cues of attention shift across an elaborated sequence.

The case is different with the interviewer and her mother-in-law: here only the interviewer consistently gazes at her interlocutor's face. The speaker gives evidence of monitoring the interviewer through her peripheral vision, but she directs her gaze away from the interviewer throughout the sequence. The consistent gaze aversion of the speaker appears to give the interviewer greater freedom to look at the speaker's face and body. The interviewer will not, after all, meet the speaker's gaze if it is reliably trained elsewhere, and thus she will not run the risk of an unseemly stretch of mutual gaze. The interviewer's freedom to gaze at the speaker directly and sustainedly appears to facilitate her close attention to the speaker's multiple, overlapping deictic gestures.

\subsubsection{A closer look at mutual gaze avoidance in the attentional sequence}

A key element of the interactions featuring gaze aversion was the consistent gaze pattern of the older, higher-status participant. The two participants to whom the interviewer would be expected to show deference - namely, the interviewer's mother-in-law and her older male acquaintance - were highly consistent in training their gaze away from the interviewer throughout their interactions. As we have noted above, this behavior freed the interviewer to look at the speakers' faces without running the risk of inappropriately meeting their gaze. Not only did the speakers appear to facilitate the interviewer's sustained gaze toward their faces, they gave evidence that they anticipated this gaze at various 
points in the interaction.

Example 5 - Older man bids for interviewer's visual attention while keeping his own gaze fixed on the ground; mutual gaze is avoided. Example (5) features the interviewer with her older male acquaintance, a pair that we anticipated would engage in gaze avoidance during their interactions. The two participants are in a side-by-side orientation, although the interviewer stands at a slight angle to orient toward the speaker. Both participants look out into the mountain range before them.

The interviewer prompts the speaker to locate two sites in roughly the same direction: Santiago Minas, a town approximately 16 kilometers from the speech location, and Oaxaca, a city at a distance of over 100 kilometers. The interviewer turns her torso and head toward the speaker as she produces the prompt - a visual attention cue that the speaker should be able to access in his peripheral vision (line 1).

The speaker continues to gaze directly forward, and begins to talk about the closer target, Santiago Minas. His response will draw attention to the fact that the town is relatively near, though it is blocked from view by the camera operator: 'it is where the woman is standing here.'

The speaker begins by dipping his head and pausing, a move that invites the already attentive interviewer to closely monitor his behavior. In a delicate coordination of gesture and speech, the speaker's head head lowers while he pronounces $n i^{A} n d w a^{B}$, 'it is,' and stays low as he pronounces $q e n^{A} n d o n^{G} n o^{A}$ qan $^{E} r e^{C}$ 'where the woman is standing here' (line 2).

Next, the speaker produces a forceful and extensive chin point: one that suggests looking over the camera operator and down into the valley beyond her. As his chin raises he pronounces, ...nga $s e^{A}-n a^{A}-n y a^{K} j a n q^{G} n i^{C}, ' \ldots$ is Santiago Minas now.' The interviewer's response to the chin point betrays just how closely she has been monitoring the speaker's face: at the very outset of his chin point, the interviewer turns her head and torso to look out toward the target town (line 3 ). 
The interviewer's turn toward the target rapidly demonstrates her shift in attention to Santiago Minas. The participants gaze together in the direction of the town as the interviewer briefly acknowledges the speaker's statement (line $4)$.

In this example, the speaker not only anticipates the gaze of the interviewer on himself, but bids for her close attention prior to the chin point. By lowering his head and pausing, the speaker draws visual attention to his face before forcefully extending his chin in a deictic gesture. The interviewer maintains her gaze on the speaker and is immediately responsive to his gesture, rapidly shifting her visual attention to the deictic target. 
(5) 20191217-R11-P04, 01:07:00
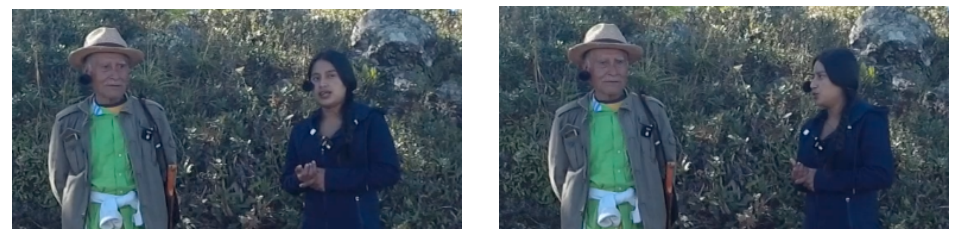

$1 \quad \mathrm{se}^{\mathrm{A}}-\mathrm{na}^{\mathrm{A}}-\mathrm{nya}^{\mathrm{K}} \mathrm{qo}^{\mathrm{E}} \mathrm{lo}^{\mathrm{J}}-\mathrm{ntqa}^{\mathrm{B}} \mathrm{la}^{\mathrm{H}}$ jyaq $^{\mathrm{F}}$ no $^{\mathrm{H}} \quad \mathrm{janq}^{\mathrm{G}} \mathrm{ni}^{\mathrm{C}}$ 'Santiago-M. and Oaxaca WHQ size NMZR DEM:D now

'Santiago Minas and Oaxaca, how far are they now?'

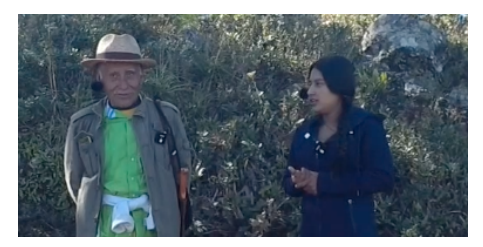

2

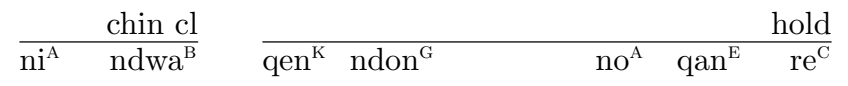

LOC be.3PL.HAB where stand.3SG.CONT NMZR woman DEM:1

'it's just where the woman is standing here'
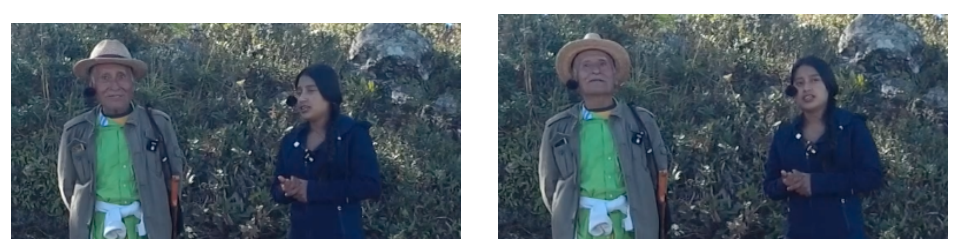

3

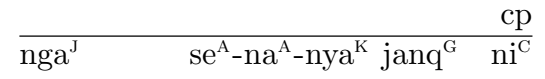

be.3SG.HAB Santiago-M. DEM:D now

'... is Santiago Minas, now'

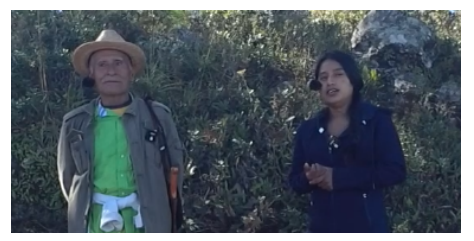

$4 \quad$ qan $^{\mathrm{F}}-$ jan $^{\mathrm{A}}$-janq ${ }^{\mathrm{F}}$

$\mathrm{ACKN}$

'uh-huh' 
Example 6 - Mother-in-law anticipates the visual attention of the interviewer while facing away from her; mutual gaze is avoided. In Example (6), the interviewer converses with her mother-in-law, a pairing that we anticipated would elicit gaze avoidance. The interviewer stands on a small outcropping of rocks, while the speaker stands just below her on the $k y q y a^{C} k c h e q^{B}$ trail. This configuration places the speaker between the interviewer and the landscape that they will discuss together.

This example begins after the interviewer has given a prompt to locate a familiar town (Zacatepec). Speaker and interviewer alike have turned their heads toward the target, a formation that they assumed after the prompt was given. The speaker supplies an initial answer that locates Zacatepec using speech, and accompanies her talk with a manual pointing gesture (line 1).

As the speaker begins to lower her pointing arm, the interviewer makes a brief verbal acknowledgement. This act suggests that, although the interviewer has been gazing out at the landscape beyond the speaker, she has seen and interpreted the pointing gesture that was part of the speaker's deictic action (line 2).

In this case the speaker has no way to visually monitor the interviewer, since the interviewer is positioned behind her. Her actions betray that she assumes the interviewer is visually attending to her. While maintaining her orientation away from the interviewer, the speaker produces a chin point towards Zacatepec, adding $l o^{A} q y a^{C} t i^{E} r e^{C}$, 'just downhill here' (line 3). The point should be visible only as a head toss from the interviewer's perspective, yet the speaker evidently relies on the interviewer to attend to the subtle signal and to interpret it as deictic.

The interviewer's response appears to confirm the speaker's expectation: just as the speaker's chin reaches the point of its fullest excursion, the interviewer shifts her gaze down to the script in her hand, signaling the attentional shift that typically follows the chin point in the core attentional sequence. The interviewer's gaze shift takes place in precisely the same frame in our video footage that the speaker's chin reaches its fullest extension. The precision timing 
of this reorientation suggests that the interviewer was indeed able to see the speaker's head movement even as she looked towards the valley beyond (line 4).

The exchange in example (6) would be unsuccessful — that is, the speaker's attempt to direct attention to the target would be unnoticed and unansweredif the participant were not reliably attentive to the movements of the speaker's head. The participants appear to share the expectation that the interviewer will consistently attend to the speaker, and their expectation supports a successful communicative exchange in this case. 
(6) 20191130-R04-P03, 00:01:28
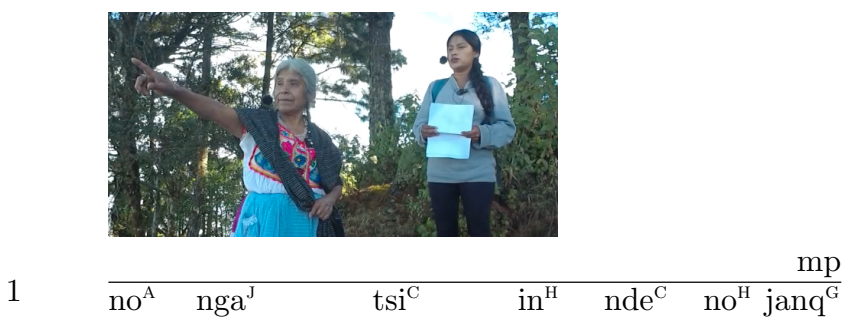

NMZR be.3SG.HAB Zacatepec DISC DEM:1 LOC DEM:D

'the one that is Zacatepec is here'

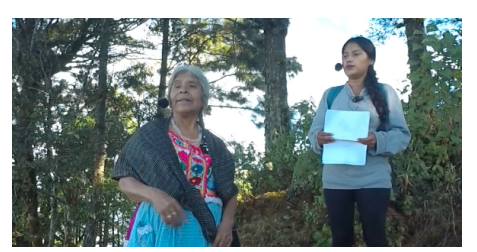

$2 \quad$ qan $^{\mathrm{A}}-$ janq $^{\mathrm{F}}$

ACKN

'uh-huh'

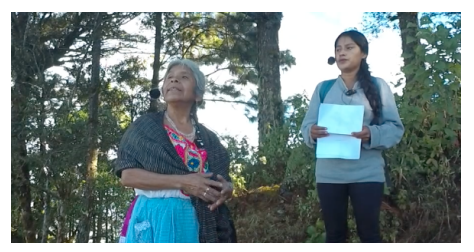

$3 \quad \mathrm{lo}^{\mathrm{A}} \mathrm{qya}^{\mathrm{C}} \quad \frac{\mathrm{cp}}{\mathrm{ti}^{\mathrm{E}} \mathrm{re}^{\mathrm{C}}} \quad \mathrm{no}^{\mathrm{H}} \quad \mathrm{janq}^{\mathrm{G}}$

just downhill LOC DEM:1 NMZR be.3SG.HAB

'it's just downhill, here'

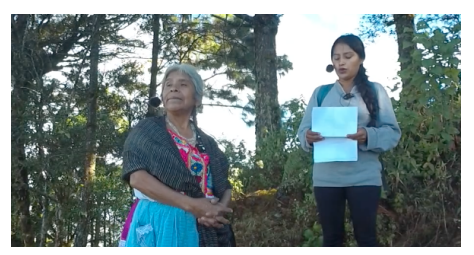

$4 \mathrm{qo}^{\mathrm{E}}$

and

'and...' ((begins new question)) 
Example 7 - Mother-in-law unexpectedly meets the gaze of the interviewer, disrupting the standard sequence. In the pairs of participants who avoided mutual gaze, the interviewer reliably attended to the participant's face while the speaker trained their gaze in another direction. This practice allowed the two participants to visually monitor one another in predictable ways: interviewer using direct gaze, and the speaker using their peripheral vision. While this practice recurred throughout our interview footage, it was not exceptionless. One unusual case provides a lens on the clash between the attentional demands and the politeness demands of pointing in the Chatino context.

In example (7), the interviewer is with her mother-in-law, a pairing that should elicit mutual gaze avoidance. The participants stand in a side-by-side orientation, and are angled slightly inwards toward one another. The kyqya ${ }^{C}$ $k c h e q^{B}$ trail extends out on either side of the pair, while they face into an open clearing.

The sequence begins with a typical prompt from the interviewer. She asks the speaker to identify the trail's endpoint at the peak of $k y q y a^{C} k c h e q^{B}$. The interviewer turns her head so that she is facing the speaker by the end of the prompt, overtly signaling her visual attention (line 1).

The speaker replies succinctly, saying only $k w i q^{B} k a n q^{G}$, 'also there.' As she speaks, she turns toward the interviewer and glances at her face. This highly unusual behavior from the speaker brings her gaze to meet the interviewer's, so that the two participants are now engaged in mutual gaze. The interviewer's response is immediate: she rapidly ducks her head and stares at the ground, avoiding the gaze of her mother-in-law (line 2).

The speaker, too, quickly makes a display of gaze aversion, though her movement is more subtle: she turns her head to gaze into the space beside the interviewer. The speaker repeats her reply: $k w i q^{B} k a n q^{G}$, 'also there.' Repetitions like this one have been described as bids for visual attention (Cf. Goodwin et al. 1980 ) and the speaker may be prompting the interviewer to return her gaze to the speaker's face. This interpretation is supported by the fact the interviewer does indeed turn her head to glance at the speaker's face (line 3). The inter- 
viewer's head turn is doubtless visible in the speaker's peripheral vision, and her show of attention may prompt the sequence that now unfolds.

The speaker repeats her locating statement one more time. As she speaks, she lowers her gaze to the ground. At just this moment, the interviewer also lowers her gaze: in this case, to the interview script. The speaker now produces a chin point, alongside a more elaborate description of the trail's endpoint (line 4). The chin point goes unobserved by the interviewer, who continues to orient to the interview script. The two participants do not achieve joint attention in this case.

Interactions like the one in Example (7) were rare in our dataset: most points were observed by the interviewer and were followed by a clearly signaled attentional shift. Examples like this one, however, serve to underscore the centrality of the participants' expectations - not only about the inappropriateness of mutual gaze in a polite interaction, but also about the interactional mechanisms available to prevent mutual gaze.

When the participant with higher social status in the interaction trained their gaze away from their interlocutor, they freed the interlocutor to give direct visual attention to their face. This facilitated the observation and interpretation of their deictic gestures. The participant with higher social status could, and did, monitor their interlocutor for cues of visual attention. Importantly, they performed this monitoring task using their peripheral vision, thereby preventing even a short stretch of mutual gaze with their interlocutor. Both participants' expectations about this practice were so well established that when the expectation was broken, the core attentional exchange surrounding a chin point could not progress. 
(7) 20191130-R04-P02, 00:04:28
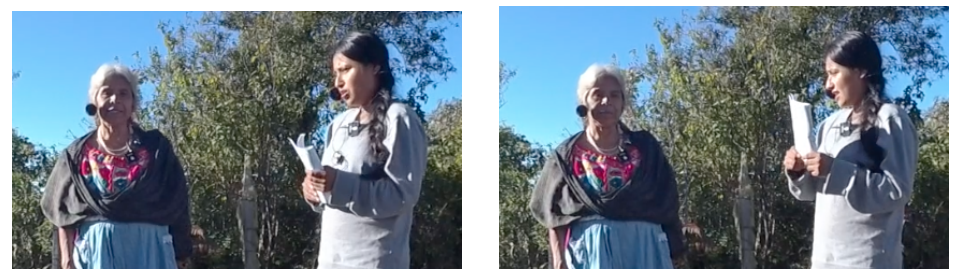

A

$$
\mathrm{qo}^{\mathrm{E}} \text { no }^{\mathrm{A}} \quad \text { nga }^{\mathrm{J}} \quad \text { kiqya }^{\mathrm{C}} \quad \text { kcheq }^{\mathrm{B}} \text { jan }^{\mathrm{G}} \text {-janq }^{\mathrm{H}}
$$

and where be.3sG.HAB mountain thorn ACKN

'and where is Thorn Mountain, hmm?'

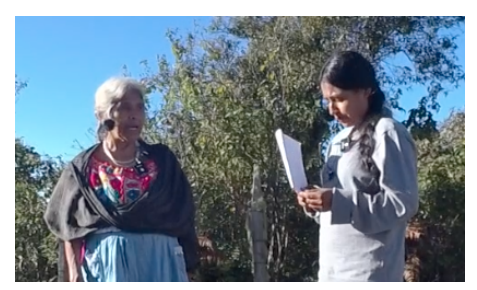

B $\mathrm{kwiq}^{\mathrm{B}} \mathrm{kanq}^{\mathrm{G}}$

also DEM:D

'also there,'

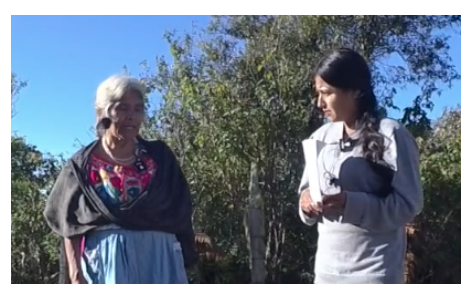

B kwiq $^{\mathrm{B}} \mathrm{kanq}^{\mathrm{G}}$

also DEM:D

'also there,'

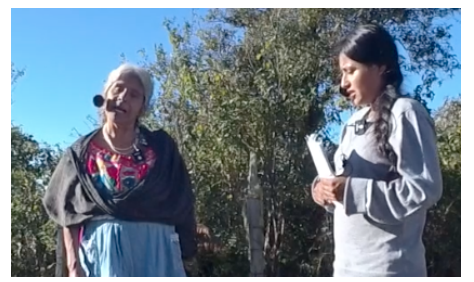

B $\quad$ kwiq $^{\mathrm{B}} \mathrm{kanq}^{\mathrm{G}} \frac{\mathrm{cp}}{\mathrm{qasa}^{\mathrm{j}}} \mathrm{lo}^{\mathrm{A}} 35$ qya $^{\mathrm{C}} \quad$ sqen $^{\mathrm{G}}$ nga $^{\mathrm{J}} \quad$ janq $^{\mathrm{G}}-\mathrm{janq}^{\mathrm{H}}$

also DEM:D until NMZR mountain exact be.3SG.HAB ACKN

'it's also there, all the way at the very top of the mountain, uh-huh' 


\section{Discussion and Conclusion}

In this study, we analyzed how participants in an indigenous Chatino setting invited, monitored, and signaled visual attention in interactions featuring deictic chin points. This was the first study to consider how the attentional demands of pointing, and the politeness demands prohibiting mutual gaze, influence the attentional choreography of the chin pointing event.

Our findings demonstrate that interactants are highly sensitive to the societal norms that regulate how attention to the head and face can be displayed. Participants are especially responsive to these demands when interacting with someone of a different social status-i.e., in situations where one participant would be expected to display deference to the other. Importantly, we have shown that interactants are equally sensitive to the attentional demands of the chin pointing act. Senders monitor the attention cues of their addressees, and produce points that they anticipate their addressees will perceive. Addresses, in turn, consistently display their visual attention to faces of senders, and display the re-direction of their attention when senders prompt them via a deictic gesture.

How, then, is chin pointing managed in polite interaction? We have shown that participants are able to meet attentional and politeness demands simultaneously, but only when they share locally established expectations about when and how each person will attend to the other's face. Such a set of shared expectations allows the participants to anticipate and respond to one another's communicative actions with precision timing, while avoiding undesirable stretches of mutual gaze. This central finding from our study underscores that chin pointing, like all deictic acts, is made possible through a shared framework for interaction: one that is rooted in knowledge not only of communicative norms, but of social ones. Chin pointing, in other words, is not only a complex interactional achievement, but also a situated social practice, and it must be analyzed as such. 


\section{Ethics Statement}

Because much of the population under study for this research is not literate, written consent for study participation and data use was not obtained. Instead, the authors created video and audio recordings of informed consent being given. Participants whose images appear in this paper gave informed consent for identifiable images of themselves to be published. The consent procedures were approved by the authorities of the San Juan Quiahije municipality, and their approval was recognized by the Swedish National Ethics Authority.

\section{Acknowledgments}

We warmly thank our interview participants: Severa Canseco Baltazar, María Orocio Nicolas, and our third participant who preferred to remain anonymous. This work would not have been possible without Chatino speaking interviewers and transcribers: we thank research assistant María Elena Mendez Cortés for interviewing all participants and for transcription and translation, Claudia García Baltazar and Rosalía Baltazar Baltazar for transcription and translation, as well as Beatríz Baltazar Canseco, Tomás Cruz Cruz, and Julian Cruz Bautista for camera operation and note-taking during our walking interviews. We thank Henrik Garde, Peter Roslund, and Jens Larsson in the Lund University Humanities Lab for support with camera piloting, data cleaning and data archiving. We gratefully acknowledge Lund University Humanities Lab and CIESAS (Centro de Investigaciones Superiores en Antropología Social) Mexico City.

Agradecemos sinceramente a las personas que participaron en nuestras entrevistas: Severa Canseco Baltazar, Maria Orocio Nicolas, y el tercer participante que pidió no ser nombrado. Este trabajo no hubiera sido posible sin el trabajo de los entrevistadores y transcriptores que hablan chatino: agradecemos a la asistente de investigación Maria Elena Mendez Cortes por entrevistar a todos los participantes y por la transcripción y traducción, a Claudia García Baltazar y a Rosalia Baltazar Baltazar por la transcripción y traducción, así 
como a Beatriz Baltazar Canseco, a Tomás Cruz Cruz y a Julian Cruz Bautista por la operación de la cámara y la toma de notas durante nuestras entrevistas. También agradecemos el trabajo de nuestros colaboradores en Suecia. Agradecemos el apoyo del Laboratorio de Humanidades de la Universidad de Lund y al Centro de Investigaciones Superiores en Antropología Social (CIESAS-CDMX).

$\mathrm{Nde}^{\mathrm{C}}$ tya $^{\mathrm{F}}$ wa $^{\mathrm{G}} \mathrm{xqwe}^{\mathrm{F}}$ qin $^{\mathrm{J}} \mathrm{nten}^{\mathrm{B}} \mathrm{no}^{\mathrm{K}} \mathrm{ntsaq}^{\mathrm{F}}$ qwa $^{\mathrm{G}}$ wra $^{\mathrm{K}} \mathrm{no}^{\mathrm{K}} \mathrm{ni}^{\mathrm{E}} \mathrm{chaq}^{\mathrm{F}}$ wa $^{\mathrm{G}}$ qin $^{\mathrm{A}}$ : Sebera $^{\mathrm{J}}$ Kanseko ${ }^{\mathrm{F}}$ Baltasar $^{\mathrm{F}}$, Liya $^{\mathrm{G}}$ Orosyo $^{\mathrm{J}}$ Nikolas $^{\mathrm{F}}$, qo ${ }^{\mathrm{E}}$ ska $^{\mathrm{A}}$ nten $^{\mathrm{B}} \mathrm{no}^{\mathrm{J}} \mathrm{ja}^{\mathrm{A}} \mathrm{la}^{\mathrm{I}} \mathrm{ngwa}^{\mathrm{C}} \mathrm{riq}^{\mathrm{C}} \operatorname{chaq}^{\mathrm{G}} \mathrm{kyaq}^{\mathrm{G}} \mathrm{ne}^{\mathrm{G}}$. Jnya ${ }^{\mathrm{F}} \mathrm{no}^{\mathrm{A}} \mathrm{nde}^{\mathrm{C}} \mathrm{ja}^{\mathrm{A}} \mathrm{la}^{\mathrm{I}}$ ngwa $^{\mathrm{C}} \operatorname{ran}^{\mathrm{F}} \mathrm{si}^{\mathrm{K}} \mathrm{no}^{\mathrm{K}} \mathrm{ja}^{\mathrm{A}}$ sqwi $^{\mathrm{I}}$ nten $^{\mathrm{B}} \mathrm{no}^{\mathrm{K}} \mathrm{ni}^{\mathrm{K}}$ chaq $^{\mathrm{F}} \mathrm{qo}^{\mathrm{E}}$ nten $^{\mathrm{B}}$ no $^{\mathrm{K}}$ nya $^{\mathrm{B}}$ chaq $^{\mathrm{F}}$ jnya $^{\mathrm{J}}$, no $^{\mathrm{A}}$ ndywiq $^{\mathrm{A}}$ chaq $^{\mathrm{F}}$ jnya $^{\mathrm{J}}$ : tya $^{\mathrm{F}}$ wa $^{\mathrm{G}} \mathrm{xqwe}^{\mathrm{F}}$ qin $^{\mathrm{J}}$ nten $^{\mathrm{B}}$ no $^{\mathrm{K}}$ $n a^{E}$ son $^{B}$, Liya $^{B}$ Lena $^{J}$ Mende $^{F}$ Korte $^{F} \operatorname{chaq}^{F} n i^{E}$ chaq $^{F}$ qin $^{J}$ tqa $^{J}$ nten $^{B}$ no $^{K}$ ntsaq $^{\mathrm{F}} \mathrm{qo}^{\mathrm{E}}$ no $^{\mathrm{A}}$ nya $^{\mathrm{B}} \mathrm{ktyi}^{\mathrm{K}}$ chaq $^{\mathrm{F}}$ jnya $^{\mathrm{J}} \mathrm{qo}^{\mathrm{E}} \mathrm{ktyi}^{\mathrm{C}}$ chaq $^{\mathrm{F}} \mathrm{xlya}^{\mathrm{K}}$, qin $^{\mathrm{A}}$ Kladiya $^{\mathrm{J}}$ Garsiqa $^{\mathrm{J}}$ Baltasar $^{\mathrm{F}} \mathrm{qo}^{\mathrm{E}}$ qin $^{\mathrm{A}}$ Rosaliya $^{\mathrm{J}}$ Baltasar $^{\mathrm{F}}$ Baltasar $^{\mathrm{F}}$ chonq $^{\mathrm{G}}$ chaq $^{\mathrm{F}}$ nya $^{\mathrm{B}}$ ktyi $^{\mathrm{K}}$ chaq $^{\mathrm{F}}$ jnya $^{\mathrm{J}}$ qo $^{\mathrm{E}}$ ktyi $^{\mathrm{C}}$ chaq $^{\mathrm{F}} \mathrm{xlya}^{\mathrm{L}}$, kwiq $^{\mathrm{J}} \mathrm{kwan}^{\mathrm{H}}$ niyan $^{\mathrm{J}}$, qin $^{\mathrm{A}}$ Beqatris $^{\mathrm{F}}$ Baltasar $^{\mathrm{F}}$ Kanseko $^{\mathrm{F}}$, qin $^{\mathrm{A}}$ Toma $^{\mathrm{H}} \mathrm{Crus}^{\mathrm{F}} \mathrm{Crus}^{\mathrm{F}}$, qo $^{\mathrm{E}}$ qin $^{\mathrm{A}} \mathrm{Jya}^{\mathrm{B}} \mathrm{Crus}^{\mathrm{F}}$ Batista $^{\mathrm{J}}$ no $^{\mathrm{A}}$ qne $^{\mathrm{G}}$ jnya $^{\mathrm{F}}$ chaq $^{\mathrm{F}}$ ylaq $^{\mathrm{J}}$ tykwan $^{\mathrm{F}}$ no $^{\mathrm{A}}$ nlyo $^{\mathrm{E}} \mathrm{kwen}^{\mathrm{E}} \mathrm{qo}^{\mathrm{E}}$ no $^{\mathrm{A}}$ nya ${ }^{\mathrm{B}} \mathrm{ktyi}^{\mathrm{C}}$ wra $^{\mathrm{K}} \mathrm{no}^{\mathrm{K}} \mathrm{ni}^{\mathrm{E}} \operatorname{chaq}^{\mathrm{F}}$ wa $^{\mathrm{G}}$ qin $^{\mathrm{A}}$ nten $^{\mathrm{B}}$. Kwiq ${ }^{\mathrm{J}} \mathrm{kwan}^{\mathrm{H}}$ niyan $^{\mathrm{J}}$ tya $^{\mathrm{F}}$ wa $^{\mathrm{G}} \mathrm{xqwe}^{\mathrm{F}}$ qin $^{\mathrm{J}}$ nten $^{\mathrm{B}}$ no $^{\mathrm{K}} \mathrm{qne}^{\mathrm{G}} \mathrm{jnya}^{\mathrm{F}}$ ti $^{\mathrm{H}}$ Swesya $^{\mathrm{J}}$. Tya ${ }^{\mathrm{F}}$ wa $^{\mathrm{G}} \mathrm{xqwe}^{\mathrm{F}}$ qin $^{\mathrm{J}}$ tqa $^{\mathrm{J}}$ nten $^{\mathrm{K}}$ no $^{\mathrm{K}}$

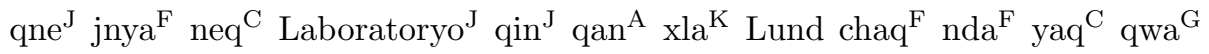
$\mathrm{qo}^{\mathrm{E}}$ qin $^{\mathrm{J}}$ nten $^{\mathrm{B}}$ no $^{\mathrm{K}} \mathrm{na}^{\mathrm{H}}$ son $^{\mathrm{B}}$ no $^{\mathrm{A}}$ nlo ${ }^{\mathrm{I}}$ qin $^{\mathrm{J}}$ qan $^{\mathrm{A}} \mathrm{xlya}^{\mathrm{K}}$ no $^{\mathrm{A}}$ qne $^{\mathrm{J}} \mathrm{xqan}^{\mathrm{H}}$ nten $^{\mathrm{B}}$ (CIESAS), kchin $^{\mathrm{A}} \mathrm{Xyaq}^{\mathrm{A}}$.

\section{Resúmenes - $\mathrm{Nde}^{\mathrm{C}} \mathrm{ntsa}^{\mathrm{B}} \operatorname{ran}^{\mathrm{K}} \mathrm{kchinq}^{\mathrm{H}} \mathrm{na}^{\mathrm{F}} \mathrm{nga}^{\mathrm{J}} \mathrm{jnya}^{\mathrm{F}} \mathrm{re}^{\mathrm{C}}$}

El señalar con la barbilla es una práctica generalizada que se emplea en todo el mundo: es una manera efectiva y muy reconocible para reorientar la atención de la receptora. Para poder notar la dirección de la barbilla, la receptora debe poner mucha atención a los movimientos de la cabeza de la emisora. Este requisito entra en conflicto con las normas de cortesía de muchas culturas ya que, con frecuencia, éstas estipulan que las participantes de las conversación deben evitar mirar fijamente el rostro y la cabeza de la otra. En este artículo ex- 
ploramos cómo los señalamientos con la barbilla se emplean satisfactoriamente en una cultura con tales características, la del grupo indígena chatino de Oaxaca, México. Analizamos diversas interacciones entre díadas de hablantes de chatino y examinamos cómo las emisoras convocan la atención visual hacia el gesto de señalamiento y cómo las receptoras marcan dicha atención mientras que, al mismo tiempo, evitan los momentos de intercambio de miradas. Encontramos que en el contexto chatino, la participante de la conversación con mayor estatus desvía la mirada de su interlocutora de manera consistente, lo que permite que la interlocutora ponga atención visualmente a su rostro sin correr el riesgo de encontrarse con la mirada de la emisora de mayor estatus y pueda prestar atención más fácilmente a los movimientos de la cabeza, incluyendo los señalamientos con la barbilla.

\footnotetext{
$\mathrm{No}^{\mathrm{A}}$ nga $^{\mathrm{J}}$ chaq $^{\mathrm{F}}$ ktsanq $^{\mathrm{B}}$ qo $^{\mathrm{K}}$ no $^{\mathrm{A}}$ nga $^{\mathrm{J}}$ swe $^{\mathrm{G}} \operatorname{tqwan}^{\mathrm{J}}-\mathrm{an}^{\mathrm{I}}$ nga $^{\mathrm{J}}$ ran $^{\mathrm{F}}$ jnya $^{\mathrm{F}}$ no $^{\mathrm{A}}$ ne $^{\mathrm{J}}$ tqa $^{\mathrm{K}}$ nten $^{\mathrm{K}}$ sha $^{\mathrm{K}}$ liyu $\mathrm{I}$ : nga $\operatorname{ran}^{\mathrm{F}} \operatorname{chaq}^{\mathrm{F}} \mathrm{la}^{\mathrm{E}} \mathrm{qa}^{\mathrm{E}} \mathrm{qo}^{\mathrm{E}} \mathrm{la}^{\mathrm{C}} \mathrm{qa}^{\mathrm{E}} \mathrm{ka}^{\mathrm{J}}$ jyaq $^{\mathrm{F}}$ riq $^{\mathrm{C}}$ nten $^{\mathrm{B}}$ no $^{\mathrm{K}}$ tqa $^{\mathrm{G}}$ ndywenq $^{\mathrm{E}}$. Chaq ${ }^{\mathrm{F}} \mathrm{ka}^{\mathrm{C}} \mathrm{ka}^{\mathrm{J}}$ jyaq $^{\mathrm{F}}$ riq $^{\mathrm{C}} \mathrm{renq}^{\mathrm{E}} \mathrm{la}^{\mathrm{H}}$

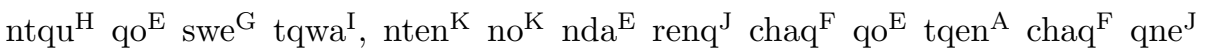
$\mathrm{qa}^{\mathrm{E}} \mathrm{kasu}^{\mathrm{K}}$ qwan $^{\mathrm{K}}$ niya $^{\mathrm{J}} \mathrm{ne}^{\mathrm{E}} \mathrm{ke}^{\mathrm{G}} \mathrm{nten}^{\mathrm{B}} \mathrm{no}^{\mathrm{K}} \mathrm{ndywiq}^{\mathrm{I}}$. Tqa ${ }^{\mathrm{J}} \mathrm{ka}^{\mathrm{E}}$ son $^{\mathrm{B}} \mathrm{no}^{\mathrm{K}} \mathrm{nde}^{\mathrm{C}}$ ndiya ${ }^{\mathrm{J}}$ tkwi $^{\mathrm{E}} \operatorname{ran}^{\mathrm{F}} \mathrm{qo}^{\mathrm{E}} \operatorname{chaq}^{\mathrm{F}}$ sqwe $^{\mathrm{F}}$ tqen $^{\mathrm{J}}$ nda $^{\mathrm{H}}$ ska $^{\mathrm{G}} \mathrm{kchin}^{\mathrm{A}} \operatorname{chonq}^{\mathrm{G}} \operatorname{chaq}^{\mathrm{F}}$, tqa $^{\mathrm{K}}$ ti $^{\mathrm{K}}$, tqen $^{\mathrm{G}}$ sqen $^{\mathrm{A}}$ nten $^{\mathrm{B}}$ no $^{\mathrm{K}}$ nda $^{\mathrm{E}} \operatorname{chaq}^{\mathrm{F}}$ ja $^{\mathrm{A}}$ la $^{\mathrm{I}}$ ndiya $^{\mathrm{I}} \operatorname{chaq}^{\mathrm{F}}$ jyaq $^{\mathrm{F}}$ nyi $^{\mathrm{A}}$ qya $^{\mathrm{H}} \mathrm{jlo}^{\mathrm{E}} \mathrm{qo}^{\mathrm{E}} \mathrm{ke}^{\mathrm{G}}$ nten $^{\mathrm{B}}$ no $^{\mathrm{K}}$ tqa $^{\mathrm{G}}$ ndywiq $^{\mathrm{I}}$. Lo $^{\mathrm{A}}$ ktyi $^{\mathrm{C}}$ no $^{\mathrm{E}}$ nde $^{\mathrm{C}}$ ndiya $^{\mathrm{J}}$ jyaq $^{\mathrm{F}}$ renq ${ }^{\mathrm{C}}$ qwan $^{\mathrm{K}}$ nya ${ }^{\mathrm{J}}$ chaq $^{\mathrm{F}}$ ndiya ${ }^{\mathrm{J}}$ riq $^{\mathrm{C}}$ tykwiq $^{\mathrm{E}} \mathrm{qo}^{\mathrm{E}}$ swe $^{\mathrm{G}}$ tqwa $^{\mathrm{A}}$ chonq $^{\mathrm{G}}$ chaq $^{\mathrm{F}}$ $\mathrm{la}^{\mathrm{E}} \mathrm{qa}^{\mathrm{E}} \mathrm{ne}^{\mathrm{J}} \mathrm{renq}^{\mathrm{I}}$ qin $^{\mathrm{A}} \operatorname{ran}^{\mathrm{F}} \mathrm{sa}^{\mathrm{A}}$ qwan $^{\mathrm{K}}$ niya ${ }^{\mathrm{J}}$ ndywiq ${ }^{\mathrm{I}} \mathrm{ti}^{\mathrm{C}} \mathrm{kwan}^{\mathrm{C}} \mathrm{re}^{\mathrm{C}}$, neq $^{\mathrm{A}}$ jnya $^{\mathrm{E}}$ no $^{\mathrm{A}}$ ndywiq $^{\mathrm{A}}$ chaq $^{\mathrm{F}}$ jnya $^{\mathrm{J}}$ qin $^{\mathrm{J}} \mathrm{lo}^{\mathrm{A}}$ tqa $^{\mathrm{B}}{\text {, } \text { shyaq }^{\mathrm{K}} \text {. Qne }}^{\mathrm{G}} \operatorname{shqan}^{\mathrm{E}}$ wa $^{\mathrm{G}}$ ska $^{\mathrm{A}}$ ska $^{\mathrm{I}}$ ti $^{\mathrm{A}}$ nya ${ }^{\mathrm{J}} \mathrm{qne}^{\mathrm{G}}$ neq $^{\mathrm{C}}$ tkwa $^{\mathrm{E}}$ nten $^{\mathrm{B}}$ no $^{\mathrm{K}}$ ndywiq $^{\mathrm{A}}$ chaq $^{\mathrm{F}}$ jnya $^{\mathrm{J}}$, qo ${ }^{\mathrm{E}}$ qan $^{\mathrm{G}}$ wa $^{\mathrm{G}}$ qwan $^{\mathrm{K}}$ niya ${ }^{\mathrm{J}} \mathrm{ne}^{\mathrm{E}} \mathrm{no}^{\mathrm{E}}$ ndywiq $^{\mathrm{A}}$, chaq $^{\mathrm{F}}$ qne $^{\mathrm{J}}$ kana $^{\mathrm{B}} \operatorname{chaq}^{\mathrm{K}}$ ni $^{\mathrm{A}} \mathrm{qya}^{\mathrm{H}}$ renq $^{\mathrm{J}}$ qwan $^{\mathrm{K}}$ niya $^{\mathrm{J}}$ sqen $^{\mathrm{I}}$ ntqu $^{\mathrm{B}} \mathrm{qo}^{\mathrm{E}} \mathrm{kwiq}^{\mathrm{J}} \mathrm{kwan}^{\mathrm{H}}$ niya $^{\mathrm{J}}$ no $^{\mathrm{A}} \mathrm{na}^{\mathrm{I}} \operatorname{chaq}^{\mathrm{F}}$ ndywiq $^{\mathrm{I}}$ renq $^{\mathrm{A}} \mathrm{ni}^{\mathrm{A}} \mathrm{qya}^{\mathrm{H}} \mathrm{sqwe}^{\mathrm{F}} \mathrm{qa}^{\mathrm{J}} \mathrm{qo}^{\mathrm{E}} \mathrm{ja}^{\mathrm{A}} \mathrm{la}^{\mathrm{I}} \mathrm{qne}^{\mathrm{J}}$ tiye $^{\mathrm{I}} \mathrm{renq}^{\mathrm{A}} \mathrm{ni}^{\mathrm{A}} \mathrm{qya}^{\mathrm{H}} \mathrm{renq}^{\mathrm{J}} \mathrm{jlo}^{\mathrm{E}}$ tqa $^{\mathrm{G}}$ renq $^{\mathrm{A}}$. Ntyja ${ }^{\mathrm{C}}$ wa $^{\mathrm{G}}$ chaq $^{\mathrm{F}}$ no $^{\mathrm{A}}$ nga $^{\mathrm{J}}$ chaq $^{\mathrm{F}}$ jnya $^{\mathrm{J}}$ in $^{\mathrm{H}}$, nten $^{\mathrm{B}}$ no $^{\mathrm{K}} \mathrm{kwan}^{\mathrm{C}}$ $\mathrm{la}^{\mathrm{E}}$ ndywiq ${ }^{\mathrm{J}} \mathrm{ja}^{\mathrm{A}} \mathrm{la}^{\mathrm{I}} \mathrm{ni}^{\mathrm{A}} \mathrm{qya}^{\mathrm{H}} \mathrm{jlo}^{\mathrm{E}} \mathrm{no}^{\mathrm{A}}$ tqa $^{\mathrm{G}}$ ndywiq $^{\mathrm{I}} \mathrm{sa}^{\mathrm{A}} \mathrm{qa}^{\mathrm{K}} \operatorname{tqen}^{\mathrm{K}} \mathrm{ka}^{\mathrm{J}} \mathrm{chaq}^{\mathrm{F}}$,
} 


$$
\begin{aligned}
& \text { kanq }^{\mathrm{G}} \operatorname{chaq}^{\mathrm{F}} \text { nda }^{\mathrm{H}} \operatorname{ran}^{\mathrm{F}} \operatorname{muru}^{\mathrm{K}} \mathrm{qin}^{\mathrm{K}} \text { no }^{\mathrm{A}} \text { tqa }^{\mathrm{G}} \text { ndywiq }^{\mathrm{I}} \operatorname{chaq}^{\mathrm{F}} \mathrm{ka}^{\mathrm{C}} \mathrm{ni}^{\mathrm{E}} \mathrm{qya}^{\mathrm{E}} \\
& \text { jlo }{ }^{\mathrm{E}} \mathrm{kwiq}^{\mathrm{J}} \mathrm{kwan}^{\mathrm{H}} \mathrm{nya}^{\mathrm{J}} \mathrm{in}^{\mathrm{H}} \mathrm{ka}^{\mathrm{C}} \mathrm{la}^{\mathrm{E}} \mathrm{ni}^{\mathrm{A}} \mathrm{qya}^{\mathrm{H}} \mathrm{qwan}^{\mathrm{K}} \mathrm{niya}^{\mathrm{J}} \mathrm{ne}^{\mathrm{E}} \mathrm{ke}^{\mathrm{G}} \mathrm{qo}^{\mathrm{E}} \mathrm{kwiq}^{\mathrm{J}} \\
& \text { qwan }^{\mathrm{K}} \text { nya }^{\mathrm{J}} \mathrm{ne}^{\mathrm{E}} \mathrm{swe}^{\mathrm{G}} \text { tqwa }^{\mathrm{A}} \text {. }
\end{aligned}
$$

\section{References}

Argyle, M., \& Cook, M. (1976). Gaze and mutual gaze. Cambridge U Press.

Atkinson, M. A., Simpson, A. A., \& Cole, G. G. (2018). Visual attention and action: How cueing, direct mapping, and social interactions drive orienting. Psychonomic bulletin \& review, 25, 1585-1605.

Bavelas, J. B., Coates, L., \& Johnson, T. (2002). Listener responses as a collaborative process: The role of gaze. Journal of Communication, 52, 566-580.

Brown, L., \& Prieto, P. (2017). (Im)politeness, prosody and gesture. In J. Culpeper, M. Haugh, \& D. Kadar (Eds.), The Palgrave Handbook of Linguistic (Im)politeness (pp. 357-379). Australia: Palgrave Macmillan.

Brown, L., \& Winter, B. (2019). Multimodal indexicality in Korean: "doing deference" and "performing intimacy" through nonverbal behavior. Journal of Politeness Research, 15, 25-54.

Brown, P., Levinson, S. C., \& Levinson, S. C. (1987). Politeness: Some universals in language usage. Cambridge University Press.

Campbell, E. (2013). The internal diversification and subgrouping of Chatino. International Journal of American Linguistics, 79, 395-420.

Ciolek, T. M., \& Kendon, A. (1980). Environment and the spatial arrangement of conversational encounters. Sociological Inquiry, 50, 237-271.

Clark, H. H. (1996). Using language. Cambridge University Press.

Cook, M. (1977). Gaze and mutual gaze in social encounter. American Scientist, $65,328-333$. 
Cooperrider, K., \& Núñez, R. (2012). Nose-pointing: Notes on a facial gesture of Papua New Guinea. Gesture, 12, 103-129.

Cruz, E. (2011). Phonology, tone and the functions of tone in San Juan Quiahije Chatino. Ph.d. dissertation, The University of Texas at Austin Austin, TX.

Cruz, H. (2014). Linguistic poetics and rhetoric of Eastern Chatino of San Juan Quiahije. Ph.d. dissertation, The University of Texas at Austin Austin, TX.

De Kadt, E. (1995). "I must be seated to talk to you": Taking nonverbal politeness strategies into account.

Doherty-Sneddon, G., \& Phelps, F. G. (2005). Gaze aversion: A response to cognitive or social difficulty? Memory \& cognition, 33, 727-733.

Dovidio, J. F., \& Ellyson, S. L. (1982). Decoding visual dominance: Attributions of power based on relative percentages of looking while speaking and looking while listening. Social Psychology Quarterly, 45, 106-113.

Duncan, S., \& Fiske, D. W. (1977). Face-to-face interaction: Research, methods, and theory. Routledge.

Eckert, P., \& Hudson, J. (1988). Wangka Wiru: A handbook for the Pitjantjatjara language learner. University of South Australia.

ELAN (Version 5.9) [Computer software] (2020). Max Planck Institute for Psycholinguistics, The Language Archive Nijmegen. Retrieved from https://archive.mpi.nl/tla/elan.

Ellyson, S. L., \& Dovidio, J. F. (). Power, dominance, and nonverbal behavior: Basic concepts and issues. In Power, dominance, and nonverbal behavior.

Enfield, N. J. (2001). 'Lip-pointing': A discussion of form and function with reference to data from laos. Gesture, 1, 185-211.

Enfield, N. J. (2009). The anatomy of meaning. Cambridge, England. 
Fehr, B. J., \& Exline, R. V. (1987). Social visual interaction: A conceptual and literature review. In A. W. Siegman, \& S. Feldstein (Eds.), Nonverbal behavior and communication (pp. 225-325). Lawrence Erlbaum Associates, Inc.

Goodwin, C. (1986). Between and within: Alternative sequential treatments of continuers and assessments. Human studies, 9, 205-217.

Goodwin, C. et al. (1980). Restarts, pauses, and the achievement of a state of mutual gaze at turn-beginning. Sociological inquiry, 50, 272-302.

Gullberg, M. (2003). Eye movements and gestures in human face-to-face interaction. In R. Radach, J. Hyona, \& H. Deubel (Eds.), The mind's eye: Cognitive and applied aspects of eye movement research (pp. 685-703). Elsevier.

Hamilton, A. F. d. C. (2016). Gazing at me: the importance of social meaning in understanding direct-gaze cues. Philosophical Transactions of the Royal Society B: Biological Sciences, 371, 20150080.

Hessels, R. S. (2020). How does gaze to faces support face-to-face interaction? a review and perspective. Psychonomic Bulletin 83 Review, 27, 856-881.

Ho, S., Foulsham, T., \& Kingstone, A. (2015). Speaking and listening with the eyes: gaze signaling during dyadic interactions. PloS one, 10, e0136905.

Instituto Nacional de Estadística Geografía e Informática (INEGI) (2020). INEGI Censo de Población y Vivienda 2020. Retrieved from: https://www.inegi.org.mx/app/areasgeograficas/?ag=202130001.

Keltner, D., Young, R. C., \& Buswell, B. N. (1997). Appeasement in human emotion, social practice, and personality. Aggressive Behavior: Official Journal of the International Society for Research on Aggression, 23, 359-374.

Kendon, A. (1967). Some functions of gaze-direction in social interaction. Acta psychologica, 26, 22-63. 
Kendon, A. (1972). Some relationships between body motion and speech. In Seigman, \& B. Pope (Eds.), Studies in dyadic communication (pp. 177-216). Pergamon Press.

Kendon, A. (1990). Conducting interaction: Patterns of behavior in focused encounters volume 7. CUP Archive.

Kendon, A., \& Cook, M. (1969). The consistency of gaze patterns in social interaction. British Journal of Psychology, 60, 481-494.

Kendrick, K. H., \& Holler, J. (2017). Gaze direction signals response preference in conversation. Research on Language and Social Interaction, 50, 12-32.

Key, M. (1962). Gestures and responses: A preliminary study among some indian tribes of Bolivia. Studies in Linguistics, 16, 92-99.

Kita, S. (2001). Locally-anchored spatial gestures, version 2: Historical description of the local environment as a gesture elicitation task. In Manual for the field season 2001 (pp. 132-135). Nijmegen, the Netherlands: Max Planck Institute for Psycholinguistics.

Kita, S., van Gijn, I., \& van der Hulst, H. (1998). Movement phases in signs and co-speech gestures, and their transcription by human coders. In I. Wachsmuth, \& M. Frölich (Eds.), Gesture and Sign Language in Human-Computer Interaction (pp. 23-35). International Gesture Workshop, Bielefeld, 17-19 September, 1997: Springer.

Kluttz, N. L., Mayes, B. R., West, R. W., \& Kerby, D. S. (2009). The effect of head turn on the perception of gaze. Vision research, 49, 1979-1993.

Levinson, S. C. (2013). Action formation and ascription. In The handbook of conversation analysis (pp. 103-130). Wiley-Blackwell.

McClave, E. (2000). Linguistic functions of head movements in the context of speech. Journal of Pragmatics, 32, 855-878. 
McClave, E., Kim, H., Tamer, R., \& Mileff, M. (2007). Head movements in the context of speech in Arabic, Bulgarian, Korean, and African-American Vernacular English. Gesture, 7, 343-390.

Mesh, K. (2017). Points of comparison: What indicating gestures tell us about the origins of signs in San Juan Quiahije Chatino Sign Language. Ph.d. dissertation The University of Texas at Austin Austin, TX.

Mesh, K. (2021). It's as far as the arm can raise: Pointing height marks target distance among the san juan quiahije chatino. Lingua, 259, 103099. URL: https://www.sciencedirect.com/science/article/ pii/S0024384121000711. doi:https://doi.org/10.1016/j.lingua.2021. 103099 .

Mesh, K., Cruz, E., \& Gullberg, M. (2021a). REaCHeS Dataset. URL: http: //hdl.handle.net/10050/00-0000-0000-0004-1F68-A@view

Mesh, K., Cruz, E., van de Weijer, J., Burenhult, N., \& Gullberg, M. (2021b). Effects of scale on multimodal deixis: Evidence from Quiahije Chatino. Frontiers in psychology, 11, 3183.

Mihas, E. (2017). Interactional functions of lip funneling gestures: A case study of Northern Kampa Arawaks of Peru. Gesture, 16, 432-479.

Mondada, L. (2007). Multimodal resources for turn-taking: pointing and the emergence of possible next speakers. Discourse Studies, 9, 194-255.

Moore, C., \& Dunham, P. J. (1995). Joint attention: Its origins and role in development. Hillsdale, NJ: Erlbaum.

Ọla Orie, d. (2009). Pointing the Yoruba way. Gesture, 9, 237-261.

Rossano, F., Brown, P., \& Levinson, S. C. (2009). Gaze, questioning and culture. Conversation analysis: Comparative perspectives, 27, 187-249.

Sacks, H., Schegloff, E. A., \& Jefferson, G. (1974). A simplest systematics for the organisation of turn-taking in conversation. Language, 50, 696-735. 
Seyfeddinipur, M. (2006). Disfluency. Evidence from Speech and Gesture. Ph.D. thesis Radboud University Nijmegen.

Sherzer, J. (1973). Verbal and nonverbal deixis: The pointed lip gesture among the San Blas Cuna. Language in Society, 2, 117.

Sicoli, M. A. (2020). Saying and doing in Zapotec: Multimodality, resonance, and the language of joint actions. Bloomsbury Publishing.

Sidnell, J., \& Enfield, N. J. (2017). Deixis and the interactional foundations of reference. In Y. Huang (Ed.), The Oxford handbook of pragmatics. Oxford University Press.

Snyder, R. A., \& Sutker, L. W. (1977). The measurement of the construct of dominance and its relationship to nonverbal behavior. The Journal of Psychology, 97, 227-230.

Streeck, J. (2014). Mutual gaze and recognition. Revisiting Kendon's "Gaze direction in two-person conversation". Essays in honor of Adam Kendon. Amsterdam: John Benjamins.

Stukenbrock, A. (2020). Deixis, meta-perceptive gaze practices, and the interactional achievement of joint attention. Frontiers in Psychology, 11, 1779. URL: https://www.frontiersin.org/article/10.3389/fpsyg. 2020.01779 doi $10.3389 /$ fpsyg. 2020.01779

Villard, S., \& Sullivant, J. R. (2016). Language documentation in two communities with high migration rates. In G. Pérez Báez, C. Rogers, \& J. E. Rosés Labrada (Eds.), Language Documentation and Revitalization in Latin American Contexts (pp. 273-304). De Gruyter.

Wilkins, D. (2003). Why pointing with the index finger is not a universal (in sociocultural and semiotic terms). In S. Kita (Ed.), Pointing: where language, culture and cognition meet (pp. 171-215). Lawrence Erlbaum Associates, Inc. 


\section{Appendix A. Chatino Orthography}

Appendix A.1. Practical orthography: correspondences with the International Phonetic Alphabet

A practical orthography was used to transcribe Quiahije Chatino for this study, rather than using the International Phonetic Alphabet (IPA). The consonant phonemes, in practical orthography and IPA, are as follows: bilabial $\mathrm{p}$ $=[\mathrm{p}], \mathrm{b}=[\mathrm{nb}], \mathrm{m}=[\mathrm{m}] ;$ apicodental $\mathrm{t}=[\mathrm{t}], \mathrm{d}=[\mathrm{nd}], \mathrm{ts}=[\mathrm{ts}], \mathrm{s}=[\mathrm{s}], \mathrm{n}=$ $[\mathrm{n}], \mathrm{r}=[\mathrm{r}], \mathrm{l}=[\mathrm{l}] ;$ laminoalveolar ty $=[\mathrm{t}], \mathrm{ny}=[\mathrm{n}], \mathrm{ly}=[\mathrm{l}]$; alveolopalatal $\mathrm{ch}$ $=[\mathrm{f}], \mathrm{x}=[\mathrm{d}], \mathrm{y}=[\mathrm{j}] ;$ Velar $\mathrm{k}=[\mathrm{k}], \mathrm{g}=[\mathrm{ng}]$; labiovelar $\mathrm{w}=[\mathrm{w}]$; glottal $\mathrm{q}=$ $[?], \mathrm{j}=[\mathrm{h}]$. The consonant phonemes, in practical orthography and IPA, are as follows: /i/, /u/, /e/, /o/, /a/. Where the IPA represents nasalized vowels with a diacritic, as in /ã/, we use a vowel followed by an $n$, as in /an/.

Appendix A.2. Transcription of tone values

Every word in Quiahije Chatino bears one tone. The tone is represented as as a capital letter at the end of the word. The tone value assignments are: $\mathrm{A}=$ [Low $], \mathrm{B}=[$ High-Low $], \mathrm{C}=[\mathrm{Mid}], \mathrm{E}=[$ High $], \mathrm{F}=[$ Low-Mid], $\mathrm{G}=[$ Low-High $]$, $\mathrm{H}=[$ Mid-superhigh $], \mathrm{I}=[$ Midhigh $], \mathrm{J}=[$ Mid-Low $], \mathrm{K}=[$ superhigh $], \mathrm{L}=[$ Low superhigh], and $\mathrm{M}=$ [superhigh Low]. 
Appendix A.3. List of Glossing Abbreviations

Speech

$\begin{array}{ll}\text { ACKN } & \text { acknowledgment token } \\ \text { COMP } & \text { completive aspect } \\ \text { CONT } & \text { continuous aspect } \\ \text { DEM:1 } & \text { demonstrative: speaker-anchored proximal } \\ \text { DEM:N } & \text { demonstrative: neutral } \\ \text { DEM:D } & \text { demonstrative: anaphoric } \\ \text { DISC } & \text { discourse marker } \\ \text { HAB } & \text { habitual aspect } \\ \text { INT } & \text { interrogative (question) marker } \\ \text { LOC } & \text { locative } \\ \text { NMZR } & \text { nominalizer } \\ \text { WHQ } & \text { wh-question }\end{array}$

Gesture

\begin{tabular}{ll}
\hline CL & chin lower \\
CP & chin point \\
MP & manual point \\
NOD & head nod
\end{tabular}

